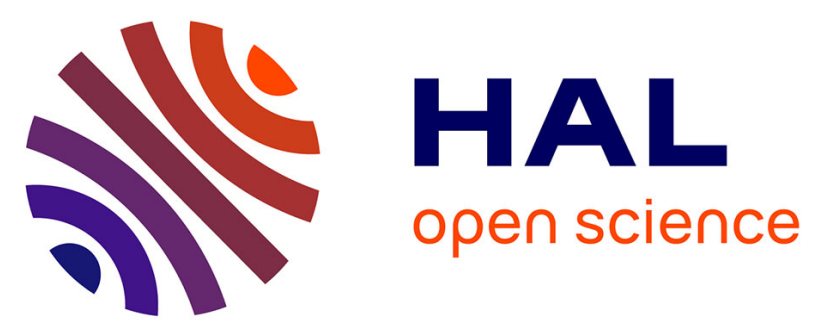

\title{
Assessing future nitrogen deposition and carbon cycle feedback using a multimodel approach: Analysis of nitrogen deposition
}

\author{
J.-F. Lamarque, J.-T. Kiehl, G.-P. Brasseur, T. Butler, P. Cameron-Smith, \\ W.-D. Collins, W.-J. Collins, Claire Granier, Didier Hauglustaine, P.-G. Hess, \\ et al.
}

\section{To cite this version:}

J.-F. Lamarque, J.-T. Kiehl, G.-P. Brasseur, T. Butler, P. Cameron-Smith, et al.. Assessing future nitrogen deposition and carbon cycle feedback using a multimodel approach: Analysis of nitrogen deposition. Journal of Geophysical Research: Atmospheres, 2005, 110 (D19), pp.D19303. 10.1029/2005JD005825 . hal-00077320

\section{HAL Id: hal-00077320 https://hal.science/hal-00077320}

Submitted on 11 Feb 2016

HAL is a multi-disciplinary open access archive for the deposit and dissemination of scientific research documents, whether they are published or not. The documents may come from teaching and research institutions in France or abroad, or from public or private research centers.
L'archive ouverte pluridisciplinaire HAL, est destinée au dépôt et à la diffusion de documents scientifiques de niveau recherche, publiés ou non, émanant des établissements d'enseignement et de recherche français ou étrangers, des laboratoires publics ou privés. 


\title{
Assessing future nitrogen deposition and carbon cycle feedback using a multimodel approach: Analysis of nitrogen deposition
}

\author{
J.-F. Lamarque, ${ }^{1}$ J. T. Kiehl, ${ }^{1}$ G. P. Brasseur, ${ }^{2}$ T. Butler, ${ }^{3}$ P. Cameron-Smith, ${ }^{4}$ \\ W. D. Collins, ${ }^{1}$ W. J. Collins, ${ }^{5}$ C. Granier, ${ }^{2,6,7}$ D. Hauglustaine, ${ }^{8}$ P. G. Hess, ${ }^{1}$ \\ E. A. Holland, ${ }^{1}$ L. Horowitz, ${ }^{9}$ M. G. Lawrence, ${ }^{3}$ D. McKenna, ${ }^{1}$ P. Merilees, ${ }^{1}$ \\ M. J. Prather, ${ }^{10}$ P. J. Rasch, ${ }^{1}$ D. Rotman, ${ }^{4}$ D. Shindell, ${ }^{11}$ and P. Thornton ${ }^{1}$ \\ Received 31 January 2005; revised 1 June 2005; accepted 7 July 2005; published 5 October 2005.
}

[1] In this study, we present the results of nitrogen deposition on land from a set of 29 simulations from six different tropospheric chemistry models pertaining to present-day and 2100 conditions. Nitrogen deposition refers here to the deposition (wet and dry) of all nitrogen-containing gas phase chemical species resulting from $\mathrm{NO}_{\mathrm{x}}\left(\mathrm{NO}+\mathrm{NO}_{2}\right)$ emissions. We show that under the assumed IPCC SRES A2 scenario the global annual average nitrogen deposition over land is expected to increase by a factor of $\sim 2.5$, mostly because of the increase in nitrogen emissions. This will significantly expand the areas with annual average deposition exceeding $1 \mathrm{gN} / \mathrm{m}^{2} /$ year. Using the results from all models, we have documented the strong linear relationship between models on the fraction of the nitrogen emissions that is deposited, regardless of the emissions (present day or 2100). On average, approximately $70 \%$ of the emitted nitrogen is deposited over the landmasses. For present-day conditions the results from this study suggest that the deposition over land ranges between 25 and $40 \mathrm{Tg}(\mathrm{N}) /$ year. By 2100, under the A2 scenario, the deposition over the continents is expected to range between 60 and $100 \operatorname{Tg}(\mathrm{N}) /$ year. Over forests the deposition is expected to increase from $10 \mathrm{Tg}(\mathrm{N}) /$ year to $20 \mathrm{Tg}(\mathrm{N}) /$ year. In 2100 the nitrogen deposition changes from changes in the climate account for much less than the changes from increased nitrogen emissions.

Citation: Lamarque, J.-F., et al. (2005), Assessing future nitrogen deposition and carbon cycle feedback using a multimodel approach: Analysis of nitrogen deposition, J. Geophys. Res., 110, D19303, doi:10.1029/2005JD005825.

\section{Introduction}

[2] The terrestrial biosphere plays a critical role in the global carbon cycle [Schimel, 1995]. While a variety of factors affects the carbon cycle in the terrestrial biosphere (e.g., temperature, precipitations, $\mathrm{CO}_{2}$ concentration, land use changes, etc.), it has recently become evident that

\footnotetext{
${ }^{1}$ National Center for Atmospheric Research, Boulder, Colorado, USA

${ }^{2}$ Max-Planck Institute for Meteorology, Hamburg, Germany.

${ }^{3}$ Max-Planck Institute for Chemistry, Mainz, Germany. USA.

${ }^{4}$ Lawrence Livermore National Laboratory, Livermore, California,

${ }^{5}$ Hadley Centre, Met Office, Exeter, UK.

${ }^{6}$ Service d'Aéronomie/Institut Pierre-Simon Laplace, Paris, France.

${ }^{7}$ CIRES/NOAA Aeronomy Laboratory, Boulder, Colorado, USA.

${ }^{8}$ Laboratoire des Sciences du Climat et de l'Environnement/Institut Pierre-Simon Laplace, Gif sur Yvette, France.

${ }^{9}$ Geophysical Fluid Dynamics Laboratory/NOAA, Princeton, New Jersey, USA. USA.

${ }^{10}$ Earth System Science, University of California, Irvine, California, USA.

${ }^{11}$ NASA Goddard Institute for Space Studies, New York, New York,
}

Copyright 2005 by the American Geophysical Union. 0148-0227/05/2005JD005825 nitrogen deposition is a key constraint on the net primary productivity [Vitousek et al., 1997; Prentice et al., 2001]. Increase in fossil fuel use and a growing population during the 20th century have led to a large increase in nitrogen deposition [Holland et al., 1997, 2005; Vitousek et al., 1997]. However, the impact of this perturbation to the nitrogen cycle on the global carbon cycle is uncertain as inconsistencies in the ecosystem response exist between models and observations [Holland et al., 1997; Jenkinson et al., 1999; Nadelhoffer et al., 1999; Throop et al., 2004]. In particular, it is likely that some ecosystems have been positively affected by this added fertilization and may have increased their carbon sequestration [Sievering, 1999]. Possibly, this increased carbon sequestration could explain a significant fraction of the $\mathrm{CO}_{2}$ "missing sink" [Schimel, 1995; Townsend et al., 1996; Holland et al., 1997], although this assessment is being disputed [Nadelhoffer et al., 1999; Prentice et al., 2001]. On the other hand, in regions where nitrogen deposition is large, sustained $\mathrm{C}$ sinks are unlikely [Schulze et al., 1989]. In addition, nitrogen-enhanced $\mathrm{CO}_{2}$ uptake may eventually become limited by soil acidification and ozone pollution, as these effects are usually present in combination with large nitrogen deposition rates [Ollinger et al., 2002; Holland et al., 2005]. The potential feedback 
between nitrogen deposition and carbon uptake could become a critical component to the evolution of the climate and needs to be assessed. As a first phase, only nitrogen deposition is analyzed in this study. In the next phase, we will calculate if the potential increased plant productivity from increased nitrogen fertilization will be able to absorb significant amounts of carbon dioxide; this will be discussed in part 2.

[3] During the 21st century, nitrogen emissions from anthropogenic sources are expected to further increase dramatically; in particular, in the A2 IPCC SRES scenario [Prather et al., 2001], the tropical regions are expected to at least double or triple their present-day emissions. Under the A2 scenario, less international cooperation is assumed than for the other scenarios, so that technology diffuses more slowly than in the other scenario families [Nakicenovic et al., 2000]. International disparities in productivity, and hence income per capita, are largely maintained or increased in absolute terms. With the emphasis on family and community life, fertility rates decline relatively slowly, which makes the A2 population the largest among the storylines (15 billion by 2100). High-income but resource-poor regions shift toward advanced postfossil technologies (renewable or nuclear), while low-income resource-rich regions generally rely on older fossil technologies. Global environmental concerns are relatively weak, although attempts are made to bring regional and local pollution under control and to maintain environmental amenities [Nakicenovic et al., 2000].

[4] Because only two of the models in this study had a representation of the chemistry and transport of ammonium, we have decided to focus our study only on the chemistry and deposition of the nitrogen-containing gas phase chemical species resulting from $\mathrm{NO}$ emissions; these species are usually referred to as $\mathrm{NO}_{\mathrm{y}}\left(=\mathrm{NO}+\mathrm{NO}_{2}+\mathrm{NO}_{3}+2 \mathrm{xN}_{2} \mathrm{O}_{5}+\right.$ $\mathrm{HNO}_{3}+$ organic nitrates). Following the emissions, the released nitrogen undergoes a series of chemical transformations (oxidation or heterogeneous reactions on particles) and deposition; this deposition can be in the form of dry deposition at the surface or wet removal in the presence of rain (mostly in the form of $\mathrm{HNO}_{3}$, even though all deposited nitrogen-containing chemical species are considered in this study).

[5] Since, at present day, $\mathrm{NH}_{3}$ emissions are comparable and slightly larger than the NO emissions [Holland et al., 1997; Galloway et al., 2004], the global estimates we describe in our study will represent approximately half of the total nitrogen deposited; this ratio is obviously region-dependent [Galloway et al., 2004]. For the rest of the paper, we will refer to $\mathrm{NO}_{\mathrm{y}}$ deposition as nitrogen deposition. In all cases, it is clear that deposition of nitrogen on land will increase in response to the increase in emissions. However, it is unclear how large this increase will be and how much it depends on different climate variables and their potential future change.

[6] To tackle the problem of the impact of nitrogen deposition, we have devised a multimodel approach with the goal of providing a lower bound on the nitrogen deposition uncertainty; parameters not considered in this study can only increase the range of estimates. For that purpose, we use a variety of models to create an ensemble from which statistics can be deduced. These models are a blend of climate models with interactive chemistry and chemistry transport models. To increase the spread of the ensemble members, while we have decided to focus on only the IPCC SRES A2 [Prather et al., 2001] scenario, the individual surface emissions of chemical species applied in each model were left unconstrained, even for present-day conditions. Finally, to reduce the computational burden, only simulations for 2000 and 2100 were performed.

[7] We have decided to focus solely on the IPCC SRES A2 scenario because it is characterized by a drastic increase of nitrogen oxides emissions (and all ozone precursors) between 2000 and 2100 . This scenario, which is viewed by many as actually unreachable, provides an upper limit on how much nitrogen oxides emissions are expected to grow during the 21 st century.

[8] In part 1 of this analysis, we will analyze the nitrogen deposition fields and provide sensitivities to climate and emissions. Part 2, which will be described in a future paper, will focus on the impact on the carbon cycle, using the deposition fields described in this paper as forcings to a land model. This full modeling exercise was named by the members of this group as the SANTA FE (Scientific Analysis of Nitrogen cycle Toward Atmospheric Forcing Estimation) project.

[9] The paper is organized as follows: in section 2, we briefly describe the models involved in the simulations, both climate and chemistry. We discuss the design of the simulations in section 3 while the boundary conditions (sea surface temperatures and emissions) are discussed in section 4 . The analysis of the modeled nitrogen deposition fields is done in section 5 , including a comparison with deposition climatologies. Conclusions are drawn in section 6 .

\section{Models}

[10] For this study, a total of twenty-nine simulations from 6 groups were performed (see Table 1) in order to examine the sensitivity of the nitrogen deposition to a variety of factors. These include sensitivity to climate (forced by changes in sea surface temperatures (SSTs)) and to emissions, including sensitivity to the lightning source of NO. Only the simulations for present-day conditions and combined 2100 climate and 2100 emissions were requested from each group for participation in this study; most of the additional simulations were performed for the further understanding of the role of climate change on nitrogen deposition.

[11] In order to create an appropriate ensemble of present and future conditions, we have created sets of monthly averaged sea surface temperatures. In all cases, the SST field (Figure 1) comes from previously performed simulations from fully coupled ocean-atmosphere models forced according to the A2 scenario [Cubasch et al., 2001]; namely we use the GISS model, the Had model, the IPSL model or, for the NCAR-labeled SST, the PCM model [Washington et al., 2000] (see below for the definition of those acronyms). To limit the impact of interannual variability, a 10-year average was used to create the 2000 and 2100 SST climatologies. From these climatologies, the $\Delta$ SST (2100-2000) was created. The so-created SST fields were then made accessible to all modeling groups; however, the $\Delta \mathrm{SST}$ from the IPSL simulations was not used by any other model because of time constraints on the project. In all cases, the SST field used in each simulation is listed in Table 1. 
Table 1. List of Simulations ${ }^{\mathrm{a}}$

\begin{tabular}{llccc}
\hline Model & SST & Climate & Emissions & Lightning \\
\hline GISS1 & GISS & 2000 & 2000 & $\mathrm{x}$ \\
GISS1 & NCAR & 2000 & 2000 & $\mathrm{x}$ \\
GISS1 & HadCM & 2000 & 2000 & $\mathrm{x}$ \\
GISS1 & GISS & 2100 & 2000 & $\mathrm{x}$ \\
GISS1 & NCAR & 2100 & 2000 & $\mathrm{x}$ \\
GISS1 & GISS & 2100 & 2100 & $\mathrm{x}$ \\
GISS2 & GISS & 2000 & 2000 & $\mathrm{x}$ \\
GISS2 & GISS & 2000 & 2100 & $\mathrm{x}$ \\
GISS2 & GISS & 2100 & 2000 & $\mathrm{x}$ \\
GISS2 & GISS & 2100 & 2100 & $\mathrm{x}$ \\
HadCM & HadCM & 2000 & 2000 & $\mathrm{x}$ \\
HadCM & HadCM & 2000 & 2100 & $\mathrm{x}$ \\
HadCM & HadCM & 2100 & 2100 & $\mathrm{x}$ \\
HadCM & HadCM & 2100 & 2100 & \\
IPSL & IPSL & 2000 & 2000 & $\mathrm{x}$ \\
IPSL & IPSL & 2100 & 2100 & $\mathrm{x}$ \\
LLNL & NCAR & 2000 & 2000 & $\mathrm{x}$ \\
LLNL & NCAR & 2100 & 2100 & $\mathrm{x}$ \\
MPIC & NCAR & 2000 & 2000 & $\mathrm{x}$ \\
MPIC & NCAR & 2100 & 2100 & $\mathrm{x}$ \\
NCAR & NCAR & 2000 & 2000 & $\mathrm{x}$ \\
NCAR & NCAR & 2000 & 2000 & \\
NCAR & NCAR & 2000 & 2100 & $\mathrm{x}$ \\
NCAR & GISS & 2100 & 2100 & $\mathrm{x}$ \\
NCAR & NCAR & 2100 & 2100 & $\mathrm{x}$ \\
NCAR & HadCM & 2100 & 2100 & $\mathrm{x}$ \\
NCAR & NCAR & 2100 & 2100 & \\
NCAR & NCAR & 2100 & 2000 & $\mathrm{x}$ \\
NCAR & NCAR & 2100 & 2000 & \\
\hline
\end{tabular}

${ }^{\mathrm{a}}$ The crosses in the lightning column indicate the consideration of the NOx lightning source in the simulation.

[12] The 2100 SST distribution (Figure 1) is characterized by an increase of the subtropical values by $1-3^{\circ} \mathrm{C}$, with annual average temperature over $32^{\circ} \mathrm{C}$ over large sections. The GISS model simulates the largest response to the 2100 forcings while NCAR simulates the smallest, reflecting differences in their climate sensitivities [Cubasch et al., 2001].

[13] Large increases in SST will translate into increases in air temperature and tropospheric water vapor and changes in precipitation location and amount. In addition, lightning location, frequency and intensity are likely to be affected as well. All these factors are in the sensitivity of nitrogen deposition to changes in climate.

[14] Using the SST fields available, four atmospheric general circulation models (GCMs) simulated the presentday and 2100 climates. Among these, three models (GISS, Had, and IPSL) performed the chemical simulations interactively using a variety of SST forcings; NCAR created the meteorological fields necessary for all the off-line chemistrytransport models.

[15] To limit the space dedicated to model description in this paper, we are only highlighting the main features of interest regarding this study. For more details, the reader is referred to the publications listed below in each model description section. A brief section summarizing the specifics most relevant to nitrogen deposition is given in section 2.3.

\subsection{General Circulation Models}

\subsubsection{NASA Goddard Institute for Space Studies (GISS)}

[16] The tropospheric chemical scheme in the new GISS model III/modelE general circulation model [Schmidt et al., 2005] is the same as that used in the earlier model $\mathrm{II}^{\prime}$
[Shindell et al., 2003], and includes basic $\mathrm{HO}_{\mathrm{x}}-\mathrm{NO}_{\mathrm{x}}-\mathrm{O}_{\mathrm{x}}$ $\mathrm{CO}-\mathrm{CH}_{4}$ chemistry and lumped families of peroxy-acetyl nitrates (PANs) and higher nonmethane hydrocarbons (isoprene, alkyl nitrates, aldehydes, alkenes, and paraffins). It uses 77 reactions among 32 species, 16 of which are transported within the GCM. Calculations are performed using a chemical time step of $30 \mathrm{~min}$. The chemistry is fully coupled with a sulfate aerosol model, which includes DMS, $\mathrm{MSA}, \mathrm{SO}_{2}$, and sulfate. Hence heterogeneous hydrolysis of $\mathrm{N}_{2} \mathrm{O}_{5}$ into $\mathrm{HNO}_{3}$ takes place on variable sulfate areas while sulfate oxidation depends upon gas phase chemistry. Photolysis rates are calculated every hour and interact with the model aerosol and cloud fields. Phase transformations of soluble species are calculated on the basis of the GCM internal cloud scheme. We include transport within convective plumes, scavenging within and below updrafts, rainout within both convective and large-scale clouds, washout below precipitating regions, evaporation of falling precipitation, and both detrainment and evaporation from convective plumes. ModelE includes a cloud tracer budget for the trace gas and aerosol species rather than returning dissolved material to the gas phase at the end of each time step. The model also includes a new dry deposition module, based on a resistance-in-series calculation [Wesely, 1989] and prescribed (i.e., uncoupled) vegetation [Matthews, 1983], which is physically consistent with the other surface fluxes (e.g., water, heat) in the planetary boundary layer scheme. Chemical calculations are performed up to the tropopause. Lightning $\mathrm{NO}_{\mathrm{x}}$ is based on the Price et al. [1997] scheme. A set of simulations was performed using a development version of modelE (hereafter identified by GISS1), which were then repeated using the release version of the GCM (GISS2). The configuration here is a 23-layer version with a top at $0.015 \mathrm{hPa}$ and $\mathrm{a} 4^{\circ} \times 5^{\circ}$ horizontal resolution.

\subsubsection{Hadley Centre (Had)}

[17] STOCHEM is a parcel trajectory model, which is run coupled to the Met Office HadCM3 climate model [Johns et al., 2003]. STOCHEM itself uses a horizontal resolution of $5^{\circ} \times 5^{\circ}$ with nine levels in the vertical. STOCHEM is fully coupled to HadCM3, which has a resolution of $3.75^{\circ} \times 2.5^{\circ}$ and 19 vertical levels, up to a model top of $4.6 \mathrm{hPa}$, and a timestep of $30 \mathrm{~min}$. Time steps for advection and chemistry are 60 and $5 \mathrm{~min}$, respectively. STOCHEM subdivides the model domain in 50,000 parcels. The model uses a chemistry scheme involving oxidation of hydrocarbons up to $\mathrm{C} 4$ and isoprene. Downward ozone fluxes (500 Tg/year) are prescribed across the $100 \mathrm{hPa}$ surface. Isoprene emissions are parameterized according to Guenther et al. [1995]. Lightning $\mathrm{NO}_{\mathrm{x}}$ emissions are parameterized according to Price and Rind [1994]. Methane emissions from wetland are interactively calculated as described by Gedney et al. [2004]. Dry deposition is interactively coupled to the land surface, depending on soil moisture, leaf area index and stomatal conductance. Wet deposition is parameterized according to Penner et al. [1994]. For present-day conditions, the emissions are from the IPCC SRES IS92a scenario [Prather et al., 2001]. For a complete model description see Sanderson et al. [2003].

\subsubsection{Institut Pierre-Simon Laplace (IPSL)}

[18] The LMDz (Laboratoire de Météorologie Dynamique, zoom) model is a grid point General Circulation Model (GCM) developed initially for climate studies by Sadourny 

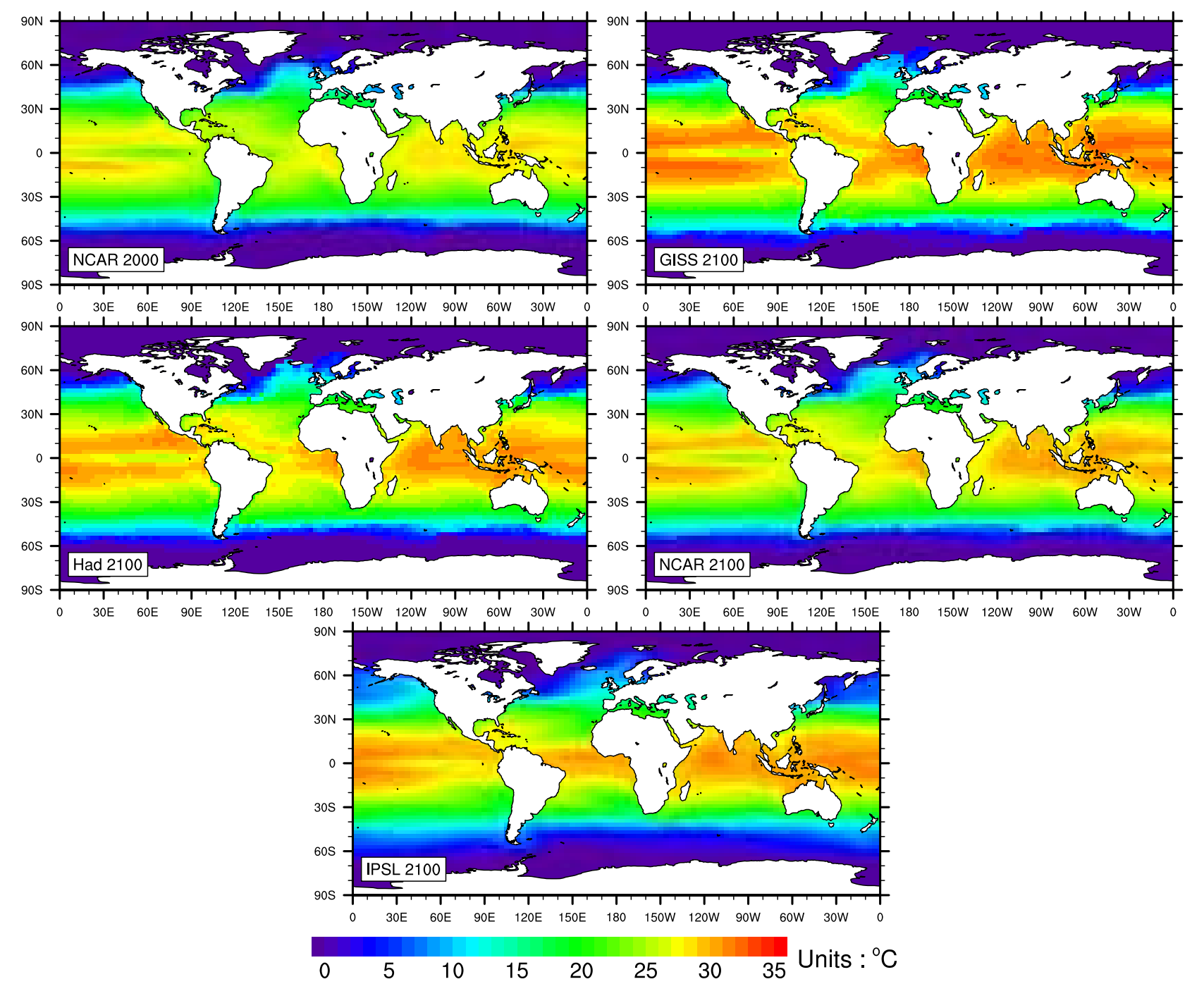

Figure 1. Sea surface temperatures for 2000 (only the one from NCAR is shown) and 2100 used by the various models in this study.

and Laval [1984]. In LMDz the finite volume transport scheme of Van Leer [1977] is used to calculate large-scale advection of tracers. The parameterization of deep convection is based on the scheme of Tiedke [1989]; a local second-order closure formalism is used to describe turbulent mixing in the planetary boundary layer (PBL). LMDz (version 3.3) has a horizontal resolution of 3.8 degrees in longitude and 2.5 degrees in latitude and uses 19 vertical $\sigma$-p levels extending from the surface to $3 \mathrm{hPa}$.

[19] The Interactive Chemistry and Aerosols (INCA) model has been integrated into LMDz. INCA includes 85 chemical species and 303 chemical reactions, and simulates tropospheric chemistry, emissions, and deposition of primary tropospheric trace species including nonmethane hydrocarbons. The anthropogenic emission inventory is based on EDGAR V3.0 [Olivier et al., 2001]. Biomass burning emissions are introduced in the model according to the satellite based inventory developed by Van der Werf et al. [2003]. The ORCHIDEE (Organizing Carbon and Hydrology in Dynamic Ecosystems) dynamical vegetation model [Krinner et al., 2005] has been used to provide biogenic surface fluxes of isoprene, terpenes, acetone, and methanol. Dry deposition velocities are calculated interactively at each time step following the resistance-in-series approach [Wesely, 1989]. The wet scavenging of soluble species is parameterized as a first-order loss process [Giorgi and Chameides, 1986].

[20] A detailed description and evaluation of LMDzINCA are given by Hauglustaine et al. [2004] and G. Folberth et al. (manuscript in preparation, 2004).

\subsubsection{National Center for Atmospheric Research (NCAR)}

[21] Two separate models were used by the NCAR group: first, the Community Atmospheric Model (CAM) was used to create the meteorological data sets needed to run the chemistry/transport models. Then the NCAR chemistry/ transport model MOZART-2 (Model for Ozone and Related chemical Tracers, version 2) was run to simulate the 2000 and 2100 chemical states. This latter model is described below with the other off-line chemistry transport models. For this work, CAM was run at a horizontal resolution of $2.8^{\circ}$ and the nominal vertical resolution of 26 levels.

[22] The Community Atmosphere Model (CAM3) represents the sixth generation of atmospheric general circulation 
models (AGCMs) developed by the climate community in collaboration with the National Center for Atmospheric Research (NCAR). CAM3 can be run either as a standalone AGCM or as a component of the Community Climate System Model (CCSM) [Collins et al., 2005]. In its standalone mode, CAM3 is integrated together with the Community Land Model [Bonan et al., 2002; Oleson et al., 2004], a thermodynamic sea ice model, and an optional slab-ocean model. For more details, see W. D. Collins et al. (Effects of increased near-infrared absorption by water vapor on the climate system, submitted to Journal of Geophysical Research, 2004).

[23] The treatments of microphysics and cloud condensate have been substantially revised in CAM3 (B. A. Boville et al., Representation of clouds and precipitation processes in the Community Atmosphere Model (CAM3), submitted to Journal of Climate, 2005). The cloud water is predicted from the prognostic cloud water parameterization of Rasch and Kristjansson [1998] updated by Zhang et al. [2003]. The new model includes separate evolution equations for the liquid and ice phase condensate. The revised scheme includes a new formulation of the fractional condensation rate and a self-consistent treatment of the evolution of water vapor, heat, cloud fraction, and in-cloud condensate [Zhang et al., 2003].

\subsection{Off-Line Chemistry Transport Models}

[24] In all cases, the off-line chemistry models listed below used the meteorological fields created by the NCAR GCM (see section 2.1.4) at the horizontal resolution of $2.8^{\circ}$ $(128 \times 64$ grid cells) and 26 vertical levels (from the ground to $\sim 4 \mathrm{hPa}$ ).

\subsubsection{Lawrence Livermore National Laboratory} (LLNL)

[25] IMPACT is a 3D off-line chemistry and aerosol transport model that predicts concentrations in the coupled troposphere and stratosphere. For the work reported here, we have used the meteorological fields generated by the NCAR model (see above) and our full NMHC ozone mechanism that covers both tropospheric and stratospheric species (88 species). The chemical mechanism includes $\mathrm{O}_{3}$, $\mathrm{NO}_{\mathrm{y}}, \mathrm{ClO}_{\mathrm{y}}, \mathrm{HO}_{\mathrm{y}}, \mathrm{BrO}_{\mathrm{y}}, \mathrm{OH}, \mathrm{PAN}, \mathrm{NO}_{\mathrm{x}}, \mathrm{CO}, \mathrm{CH}_{4}, \mathrm{HNO}_{3}$, isoprene, ethane, propane, various ketones and aldehydes, and their products. The mechanism is based on Lurmann et al. [1986] with various modifications. It is fully described in Rotman et al. [2004]. The absorption cross sections and reaction rate coefficients follow DeMore et al. [1997] and Sander et al. [2000]. Photolysis is based on a clear sky lookup table using the methodologies from Douglass et al. [1997]; rates are adjusted for clouds. The chemical equations are solved using the Gear solver (SMVGEAR II) of Jacobson [1995].

[26] The IMPACT model uses the operator splitting technique for emissions, advection, diffusion, convection, deposition, gravitational settling, photolysis, and chemistry. Advection is based on a version of the Lin and Rood [1996] scheme, and uses a pressure-fixer scheme to ensure conservation of tracer mass [Rotman et al., 2004]. Diffusion is based on the implicit scheme of Walton et al. [1998]. Convection is based on the CONVTRANS algorithm of Rasch et al. [1997]. Wet deposition of species is based on their Henry's law coefficient, and is handled separately for scavenging within convective updrafts, the rest of the convective system, and stratiform clouds. Our scheme is based on Giorgi and Chameides [1986], Balkanski et al. [1993], Mari et al. [2000], and Liu et al. [2001]. Dry deposition uses the resistances in series approach based on Wesely et al. [1985], Wesely [1989], and Wang et al. [1998]. Gravitational settling of particles is based on Seinfeld and Pandis [1998]. The 2000 emissions used for this work came from Granier et al. [2004], except for $\mathrm{NO}_{x}$ from lightning and aircraft, and $\mathrm{CH}_{4}$, for which we used our standard 1990s emissions [Rotman et al., 2004] for both 2000 and 2100 .

\subsubsection{Max-Planck Institute for Chemistry (MPIC)}

[27] The global offline Model of Atmospheric Transport and Chemistry - Max Planck Institute for Chemistry version 3.2 (MATCH-MPIC) is described and evaluated by Rasch et al. [1997], Mahowald et al. [1997a, 1997b], Lawrence et al. [1999], von Kuhlmann et al. [2003a, 2003b], and Lawrence et al. [2003, and references therein].

[28] The meteorology component of MATCH-MPIC simulates advective transport [Rasch and Lawrence, 1998], convection [Zhang and McFarlane, 1995; Hack, 1994], vertical diffusion [Holtslag and Boville, 1993], cloud fractions [Slingo, 1987], and cloud microphysics [Rasch and Kristjansson, 1998]. Gridded values for basic meteorological parameters (pressure, temperature, horizontal winds, surface heat fluxes, and surface stresses) are obtained from the NCAR model simulations (see above). The remaining meteorological properties (e.g., convective cloud transport) are diagnosed online within MATCH-MPIC. MATCHMPIC has a full tropospheric hydrological cycle; the surface source of water vapor is computed from the latent heat flux in the input meteorological data, and the moisture transport and precipitation are computed using the algorithms in MATCH-MPIC. This gives a water vapor distribution which is internally consistent with the model's meteorology.

[29] For both the 2000 case and the 2100 case, the model was initialized with mean trace gas fields from von Kuhlmann et al. [2003a], with a 4 month spin-up for the chemical fields. The photochemical scheme includes a parameterization of nonmethane hydrocarbon (NMHC) oxidation covering up to C5 molecules (especially isoprene), and subgridscale transport and the hydrological cycle are diagnosed online. Further details can be found via http://www.mpch-mainz.mpg.de/ lawrence.

\subsubsection{National Center for Atmospheric Research (NCAR)}

[30] The MOZART-2 chemistry transport model was originally developed at the National Center for Atmospheric Research, the Geophysical Fluid Dynamics Laboratory and the Max-Planck Institute for Meteorology to study tropospheric chemistry. For a complete description of the model and its evaluation, the reader is referred to Horowitz et al. [2003, and references therein].

[31] MOZART-2 provides the distribution of 80 chemical constituents (including some nonmethane hydrocarbons) between the surface and the stratosphere. The evolution of species (transport and chemistry) is calculated with a time step of $20 \mathrm{~min}$.

[32] Dry deposition velocities are calculated interactively using a resistance-in-series scheme [Wesely, 1989; Walmsley and Wesely, 1996; Wesely and Hicks, 2000]. The calculation 

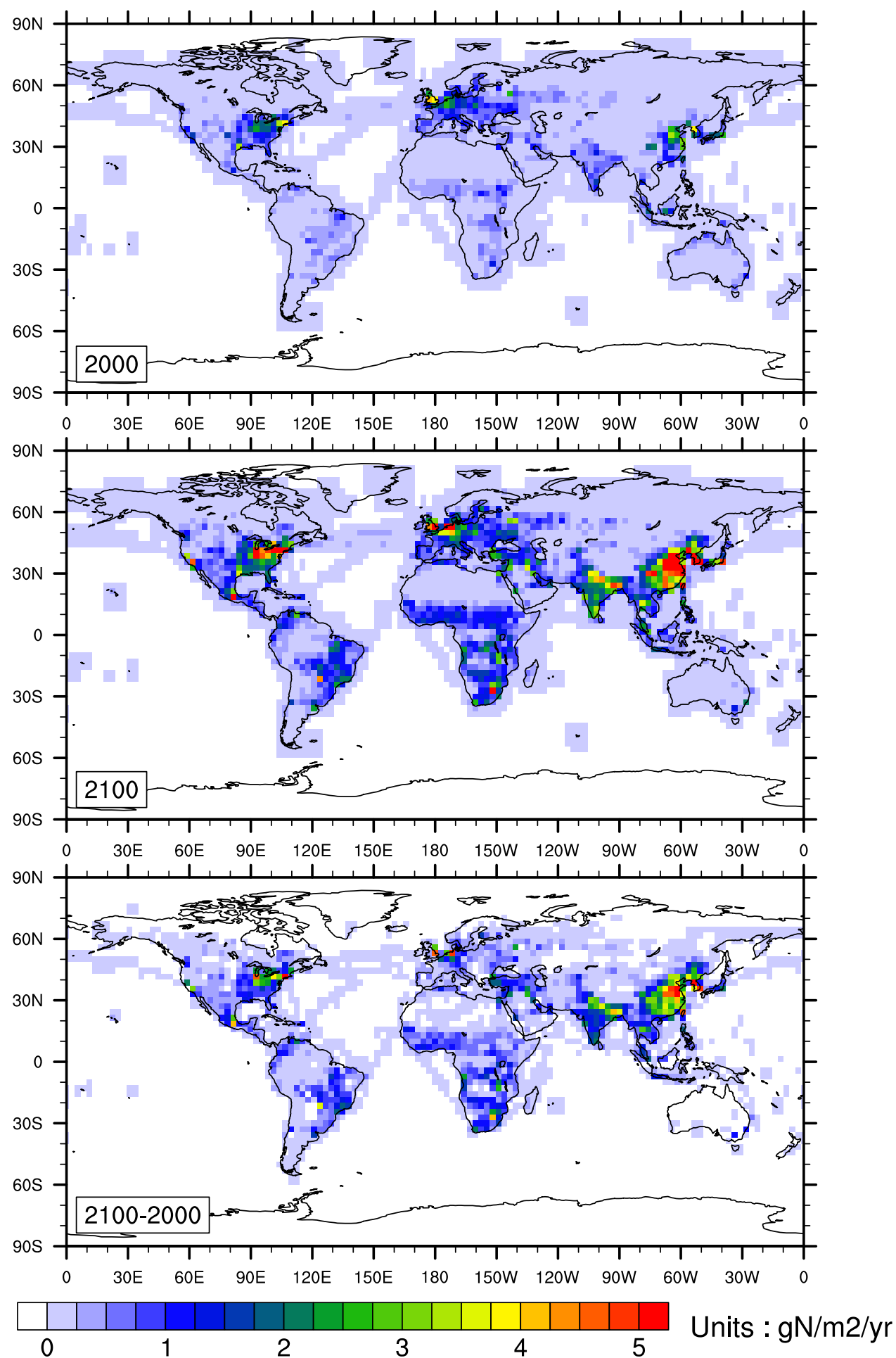

Figure 2. Annual total surface $\mathrm{NO}_{\mathrm{x}}$ emissions (in $\mathrm{gN} / \mathrm{m}^{2} /$ year) for 2000,2100 , and their difference used for the NCAR model. Others models have similar geographical distribution and are therefore not displayed.

of surface resistances uses the vegetation distribution of Bonan et al. [2002].

[33] Wet deposition is represented as a first-order loss process within the chemistry operator, with loss rates computed on the basis of the large-scale and convective precipitation rates diagnosed by MOZART-2 [Rasch et al., 1997; Horowitz et al., 2003]. Soluble species undergo wet removal by in-cloud scavenging, using the parameterization of Giorgi and Chameides [1986] based on their temperature-dependent effective Henry's Law constants. In addi- 
Table 2. Summary of NOx Emissions (as $\operatorname{Tg}(\mathrm{N}) /$ year) for Year 2000 and 2100, Including the Range of Lightning Emissions (for All Climate States) ${ }^{\mathrm{a}}$

\begin{tabular}{lccc}
\hline Model & 2000 & 2100 & Lightning \\
\hline GISS1/2 & 35 & 119 & $6-13.5$ \\
Had & 57 & 105 & NA \\
IPSL & 45 & 123 & 5 \\
LLNL & 45 & 118 & 5 \\
MPIC & 37 & 131 & 2 \\
NCAR & 45 & 118 & $2.2-2.8$ \\
\hline
\end{tabular}

${ }^{\text {a}}$ Please note that Had did not provide the lightning source amount separately.

tion, highly soluble species (such as $\mathrm{HNO}_{3}$ and $\mathrm{H}_{2} \mathrm{O}_{2}$ ) are also removed by below-cloud washout, using the formulation described by Brasseur et al. [1998].

[34] The $\mathrm{NO}_{\mathrm{x}}$ production by lightning follows the Price and Rind [1994] and Price et al. [1997] parameterization, as discussed by Horowitz et al. [2003]. It is scaled to a specified global annual amount; in our case, we specify this amount to be $5 \operatorname{Tg}(\mathrm{N}) / y e a r$ (as in the work by Gauss et al. [2003]) and calculated the scaling factor for the 2000 case. The same scaling was then applied to all simulations. The 2000 surface emissions are from Granier et al. [2004].

\subsection{Summary}

[35] All the models used in this study include a representation of nitrogen oxides chemistry, wet deposition and dry deposition. Regarding the chemistry, all models have a reasonable description of the chemistry relevant to nitrogen species; in particular, all models include the heterogeneous hydrolysis of $\mathrm{N}_{2} \mathrm{O}_{5}$ into $\mathrm{HNO}_{3}$. The largest differences arise from the way higher hydrocarbons are handled. The wet depositions schemes are based (using different extensions) originally on the first-order loss scheme devised by Giorgi and Chameides [1986]. This scheme links the wet removal of soluble species (using an effective Henry's law approach) to the occurrence of precipitation. The dry deposition is parameterized using schemes based on the resistance approach devised by Wesely [1989]. Finally, all models use a lightning parameterization (a nonsurface source of NO) based on the Price and Rind [1994] approach. Therefore all models are similar in their overall design; however each model will differ from extensions of the original schemes and model specific parameters.

\section{Protocol for Model Output of Nitrogen Deposition}

[36] All the models were run for at least 2 years. In order to evaluate the interannual variability of nitrogen deposition, several simulations were extended to a maximum of 10 years. Separate wet and dry nitrogen deposition fields (expressed in $\mathrm{kg}(\mathrm{N}) / \mathrm{m}^{2} /$ year) were saved as monthly averages.

[37] The nitrogen deposition is calculated as the sum of the deposition of all species forming $\mathrm{NO}_{\mathrm{y}}$. Of those, a large fraction (larger than half in many places) is through the deposition of nitric acid $\left(\mathrm{HNO}_{3}\right)$. The rest is through the deposition of $\mathrm{NO}_{\mathrm{x}}$ (dry deposition only) and organic nitrates (such as peroxyacetylnitrate, PAN).

[38] The ultimate goal of this study will be to model the impact of nitrogen deposition on the carbon cycle as modeled in the Community Land Model (CLM) [Bonan et al., 2002; Oleson et al., 2004]; therefore these deposition fields were conservatively interpolated to the CLM T31 grid, on which these experiments will be performed. The analysis presented in this study only uses these regridded fields as it allows for a direct comparison of the various model simulations.

\section{Emission of Nitrogen Oxides}

[39] As mentioned in the Introduction, large changes in the emissions of nitrogen oxides (the only significant source of nitrogen containing compounds in this study) are expected to occur under the A2 scenario. This scenario emphasizes the development of large $\mathrm{NO}_{\mathrm{x}}$ sources in the tropical and Asian regions by 2100 [Prather et al., 2001].

[40] We display in Figure 2 the NCAR surface $\mathrm{NO}_{\mathrm{x}}$ emissions (including anthropogenic and natural but neither lightning nor aircraft) for 2000, 2100 and their difference. While no constrains were laid on the set of emissions used

Table 3. Summary of Comparison of Modeled Present-day Nitrogen Wet Deposition With Observations Over Europe, North America, and Asia ${ }^{\mathrm{a}}$

\begin{tabular}{|c|c|c|c|c|}
\hline & Mean & Median & $\begin{array}{l}\text { Standard } \\
\text { Deviation }\end{array}$ & $\begin{array}{l}\text { Correlation } \\
\text { Coefficient }\end{array}$ \\
\hline & & $E M E P$ & & \\
\hline Observations & 0.32 & 0.31 & 0.21 & \\
\hline \multicolumn{5}{|l|}{ Model } \\
\hline GISS1 GISS & 0.34 & 0.28 & 0.22 & 0.26 \\
\hline GISS2 GISS & 0.38 & 0.30 & 0.28 & 0.26 \\
\hline GISS1 Had & 0.32 & 0.26 & 0.21 & 0.25 \\
\hline GISS1 NCAR & 0.27 & 0.22 & 0.17 & 0.22 \\
\hline Had Had & 0.17 & 0.17 & 0.06 & 0.44 \\
\hline IPSL IPSL & 0.29 & 0.24 & 0.16 & 0.38 \\
\hline LLNL NCAR & 0.30 & 0.23 & 0.17 & 0.24 \\
\hline MPIC NCAR & 0.23 & 0.22 & 0.12 & 0.35 \\
\hline NCAR NCAR & 0.25 & 0.22 & 0.10 & 0.29 \\
\hline \multirow[t]{2}{*}{ Model average } & 0.28 & 0.24 & 0.16 & 0.30 \\
\hline & & $N A D P$ & & \\
\hline Observations & 0.19 & 0.20 & 0.12 & \\
\hline \multicolumn{5}{|l|}{ Model } \\
\hline GISS1 GISS & 0.23 & 0.23 & 0.12 & 0.85 \\
\hline GISS2 GISS & 0.25 & 0.23 & 0.15 & 0.84 \\
\hline GISS1 Had & 0.20 & 0.21 & 0.12 & 0.85 \\
\hline GISS1 NCAR & 0.21 & 0.20 & 0.12 & 0.82 \\
\hline Had Had & 0.20 & 0.22 & 0.10 & 0.87 \\
\hline IPSL IPSL & 0.20 & 0.14 & 0.14 & 0.75 \\
\hline LLNL NCAR & 0.28 & 0.19 & 0.23 & 0.77 \\
\hline MPIC NCAR & 0.19 & 0.18 & 0.12 & 0.86 \\
\hline NCAR NCAR & 0.19 & 0.16 & 0.13 & 0.81 \\
\hline \multirow[t]{2}{*}{ Model average } & 0.21 & 0.20 & 0.14 & 0.83 \\
\hline & & EANET & & \\
\hline Observations & 0.26 & 0.23 & 0.19 & \\
\hline \multicolumn{5}{|l|}{ Model } \\
\hline GISS1 GISS & 0.14 & 0.08 & 0.10 & 0.58 \\
\hline GISS2 GISS & 0.14 & 0.07 & 0.11 & 0.54 \\
\hline GISS1 Had & 0.13 & 0.07 & 0.09 & 0.62 \\
\hline GISS1 NCAR & 0.13 & 0.08 & 0.09 & 0.62 \\
\hline Had Had & 0.18 & 0.11 & 0.09 & 0.41 \\
\hline IPSL IPSL & 0.22 & 0.09 & 0.15 & 0.47 \\
\hline LLNL NCAR & 0.17 & 0.06 & 0.12 & 0.59 \\
\hline MPIC NCAR & 0.18 & 0.08 & 0.12 & 0.70 \\
\hline NCAR NCAR & 0.20 & 0.11 & 0.11 & 0.67 \\
\hline Model average & 0.16 & 0.08 & 0.11 & 0.58 \\
\hline
\end{tabular}

${ }^{\mathrm{a} O b s e r v a t i o n a l ~ n e t w o r k s: ~ E u r o p e, ~ E M E P ; ~ N o r t h ~ A m e r i c a, ~ N A D P ; ~ A s i a, ~}$ EANET. Units are $\mathrm{gN} / \mathrm{m}^{2} /$ year. 

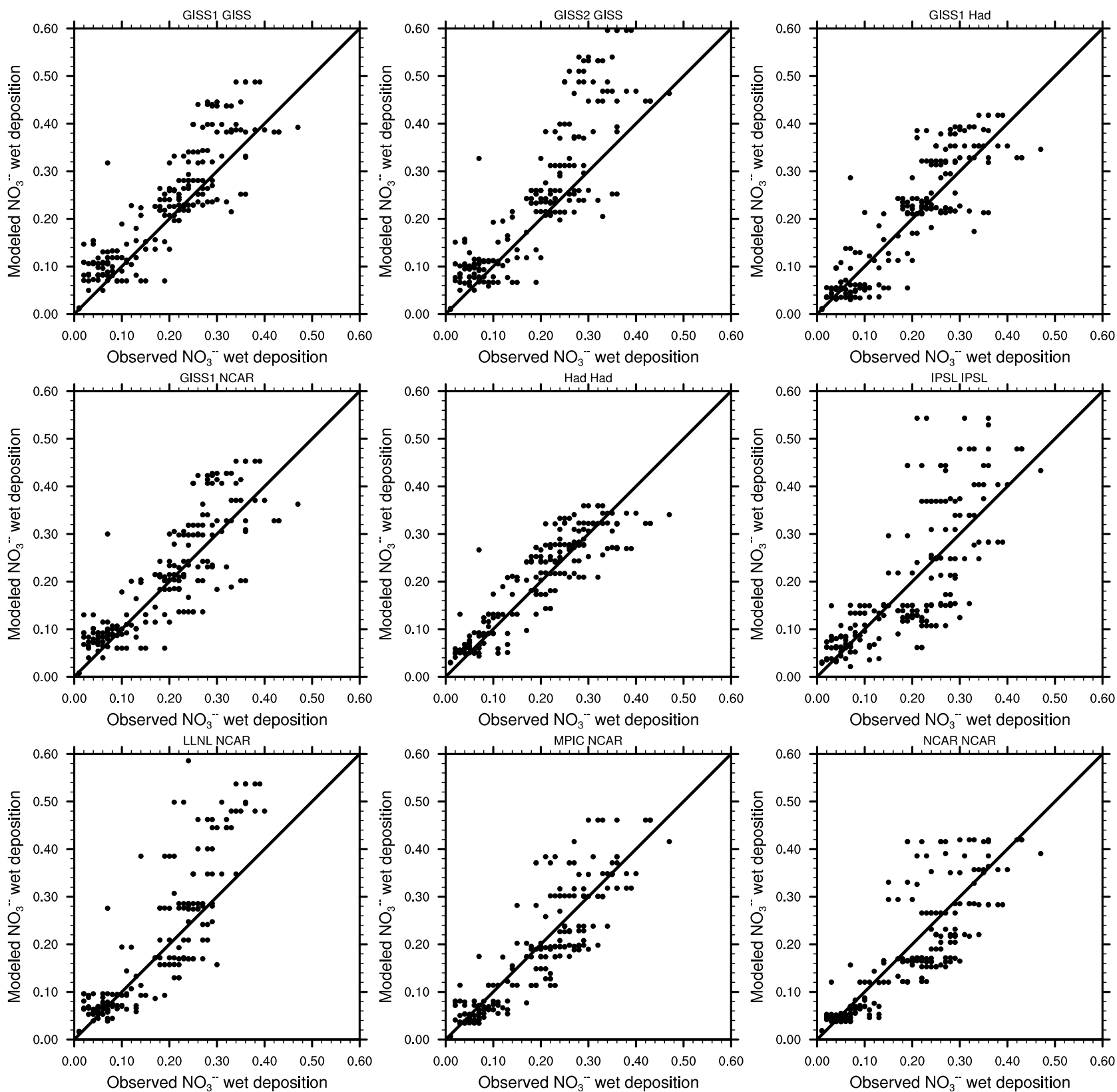

Figure 3a. Scatterplot of the modeled nitrogen annual wet deposition rate (in $\mathrm{gN} / \mathrm{m}^{2} /$ year) versus the observed $\mathrm{NO}_{3}^{-}$annual wet deposition over North America (NADP network). Over each plot is the reference to the model used, followed by the SST field used.

by the individual models, the overall distribution of $\mathrm{NO}_{\mathrm{x}}$ emissions and their changes is quite similar between models (not shown). The largest changes are found over eastern Asia where the emissions are found to increase by a factor of 4 according to the A2 scenario; these changes are from anthropogenic emissions only as no changes in emissions from soils were considered. However, significant changes are also set to occur over the already large sources of western Europe and North America. In addition, widespread increases are expected to occur over Africa, South America and the Indian subcontinent. Finally point sources from megacities (such as Mexico City and Sao Paulo) are expected to become significant contributors to the global budget of nitrogen. Similar conclusions can be drawn from the other emission inventories used in this study.

[41] Estimates for the globally integrated $\mathrm{NO}_{\mathrm{x}}$ sources considered in this study range between 35 and $50 \mathrm{Tg}(\mathrm{N}) /$ year for 2000 (see Table 2) and between 105 and $131 \mathrm{Tg}(\mathrm{N}) /$ year for 2100; a significant intermodel variability arises from the biomass burning emissions. The lightning source contributes an additional 2 to $13.5 \mathrm{Tg}(\mathrm{N}) /$ year. Among the models used, the largest sensitivity (a factor of 2) of the NO source from lightning to changing the climate was found for the GISS model using the GISS 2100 SST. On the other hand, the lightning source in the NCAR 

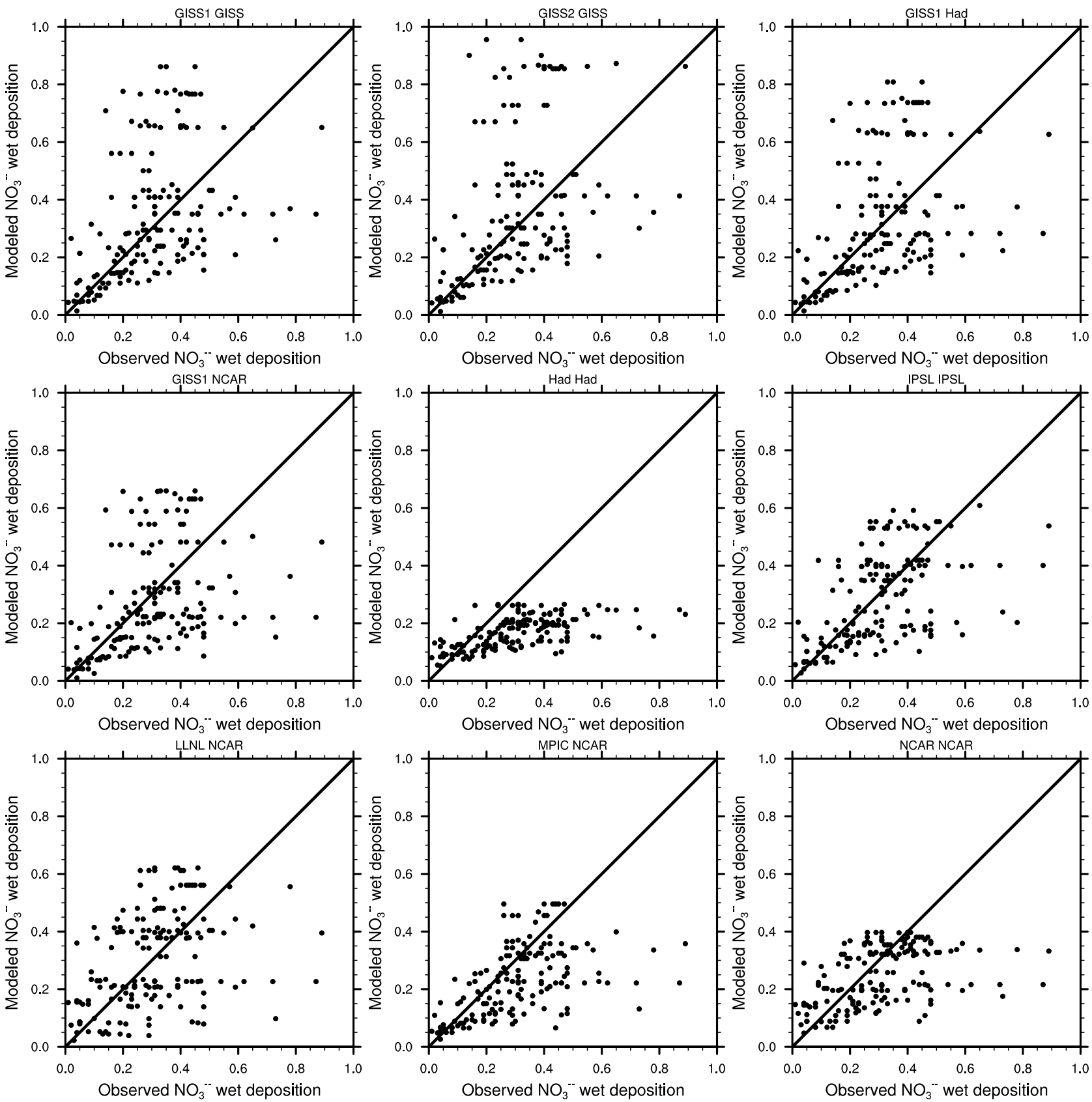

Figure 3b. Same as Figure 3a but for wet deposition over western Europe (EMEP network).

model shows much smaller sensitivity to changes in the climate, of the order of $30 \%$.

\section{Analysis of Nitrogen Deposition}

\subsection{Evaluation of Present-Day Results}

[42] Realistic representation of wet nitrogen deposition requires the combined accurate simulation of precipitation (location and intensity), soluble nitrogen loading, and aqueous uptake. As part of the monitoring of acid rain, extensive networks of wet deposition were built in western Europe (EMEP: $35^{\circ} \mathrm{N}$ to $70^{\circ} \mathrm{N}, 10^{\circ} \mathrm{W}$ to $45^{\circ} \mathrm{E}$ ) and North America (NADP: $27^{\circ} \mathrm{N}$ to $50^{\circ} \mathrm{N}, 125^{\circ} \mathrm{W}$ to $60^{\circ} \mathrm{E}$ ); maps with the location of the measurement sites are shown by Holland et al. [2005]. Frequent measurements were taken over a long period of time, providing enough data to create climatologies. We use a database of such measurements [Holland et al., 2005] to evaluate the models' ability to reproduce the present-day levels of nitrogen deposition over these two regions. Since all chemical models have different resolutions, the model results (taking into account all wet deposited nitrogen-containing species available in each model) and the nitrate measurements (only annual averages are used in this study) are averaged at the T31 CLM resolution (see section 3). Statistical analysis of these data is shown in Table 3.

[43] At the NADP stations (Figure 3a), the models tend to reproduce the range of observed values, with all models showing spatial correlation coefficients larger than 0.75 . There is however the indication that, for large observed 

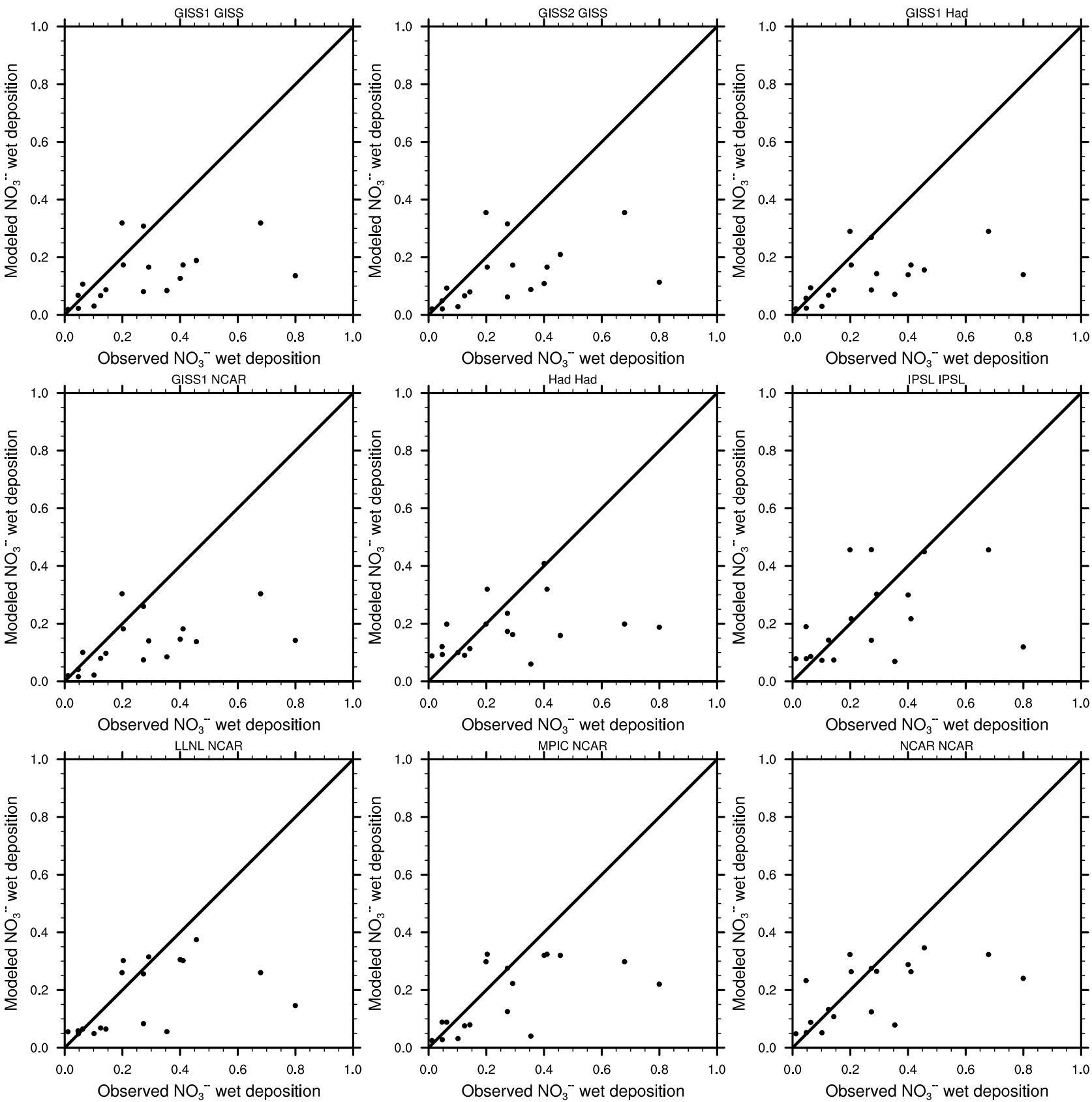

Figure 3c. Same as Figure 3a but for wet deposition over Asia (EANET network).

deposition rates, all models tend to overpredict nitrogen wet removal. A possible explanation is that, since the uptake of nitric acid on aerosols is not considered in our set of models, the wet deposition might be overestimated because of the longer lifetime of ammonium nitrate ( $\sim 6$ days) compared to nitric acid ( $\sim 4$ days); this process is most likely to be of importance in the highly polluted regions. On average, the models slightly overestimate the mean deposition rate, slightly underestimate the median, and provide a good description of the geographical variability (indicated by the standard deviation). The average correlation coefficient is 0.83 . Overall there is clear indication that the annual deposition rate is quite well reproduced in all simulations over North America.
[44] In the case of EMEP (Figure 3b, note the different scale), most models (except Had and NCAR) are characterized by an underestimate at low deposition rates and overestimate at medium to high rates. The highest observed deposition rates are underestimated by all models, regardless of the underlying 2000 SST used. On average, the models provide an underestimate of the observed deposition rate (by approximately 15\%), the median (by over $25 \%$ ), the standard deviation, and a correlation coefficient of 0.31 . The lack of good spatial correlation might also be attributed to the missing representation of ammonium nitrate in the models as the concentration of this aerosol can be quite large over western Europe (not shown). 


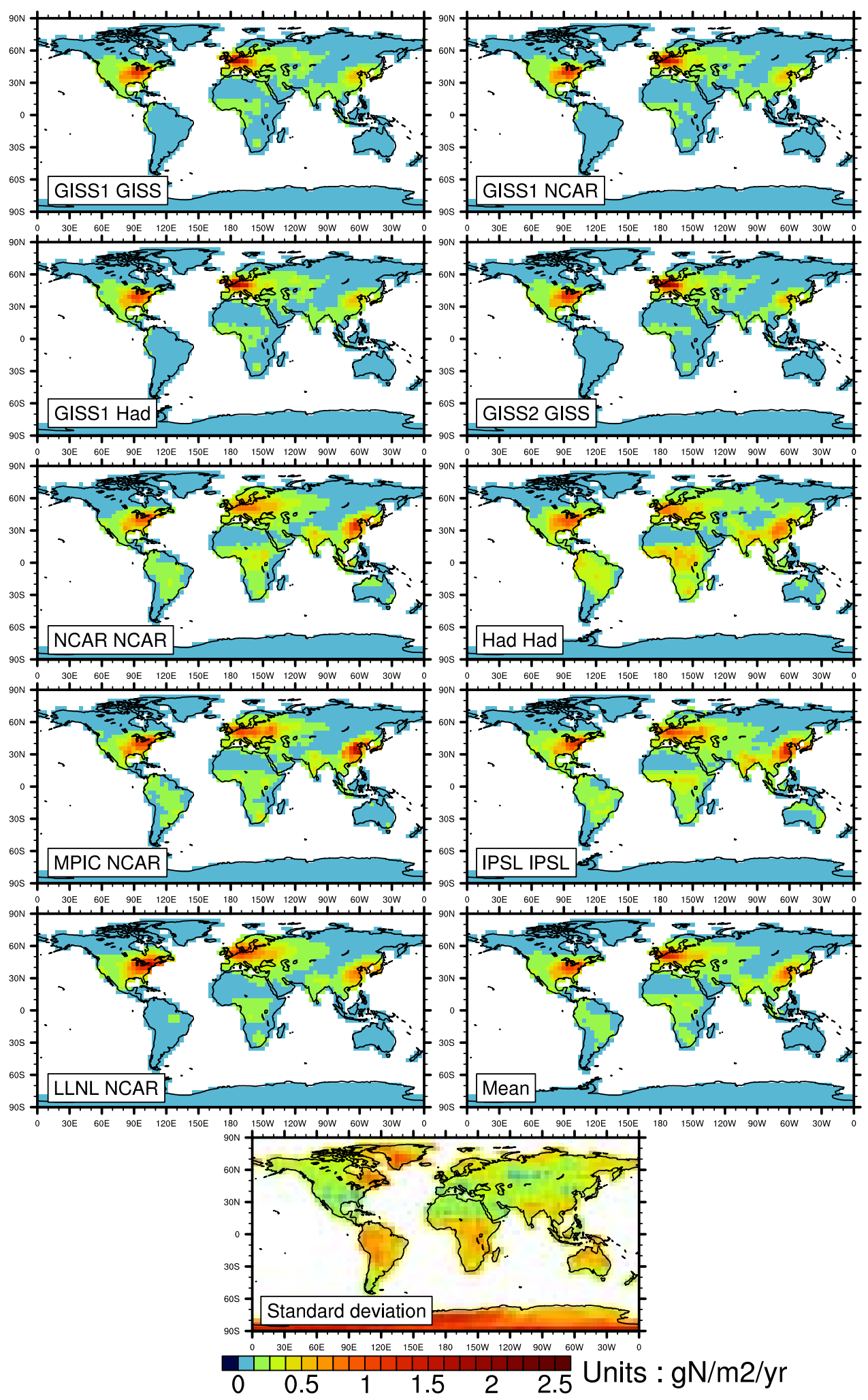

Figure 4a. Global distribution of the annual average total nitrogen deposition rate (in $\mathrm{gN} / \mathrm{m}^{2} /$ year) over land areas in 2000. Each plot is referenced by the model used, followed by the SST field used. In addition, the last two plots are the mean of all the models and its standard deviation (expressed in fraction: a value of 1 corresponds to $100 \%$ ). 


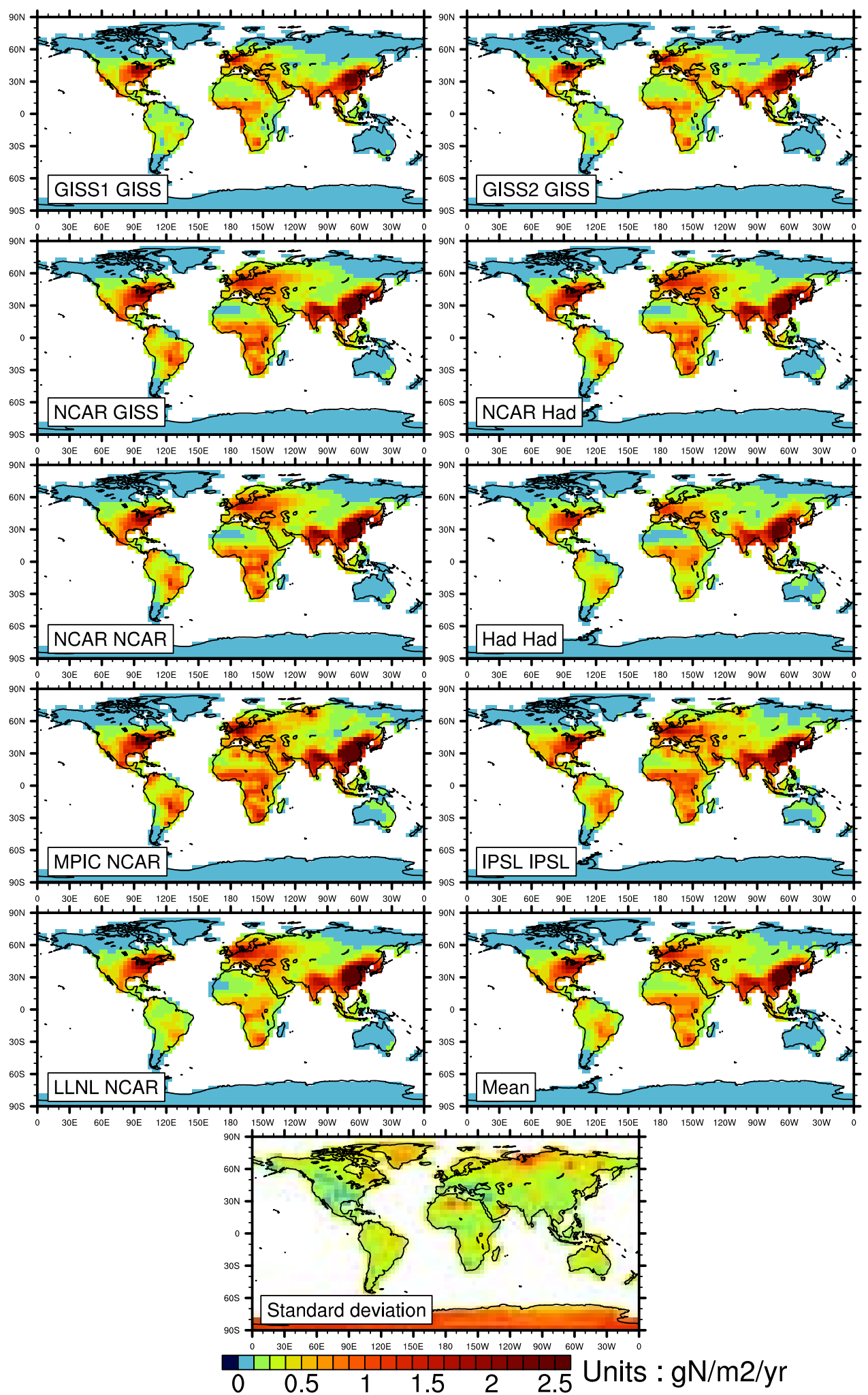

Figure 4b. Same as Figure 4a but for 2100.

[45] These fairly poor results contrast with the good simulations over the NADP network described above. The main difference between the two networks is probably their geographical distribution. In North America, most of the sites are in fairly rural settings, away from the main emission centers; on the other hand, this cannot be achieved in Europe because of the overall higher population density. Because of the coarse model grids, the large deposition rates (likely to be downwind from high pollution centers) are likely to be underestimated. Another possibility is a sys- 

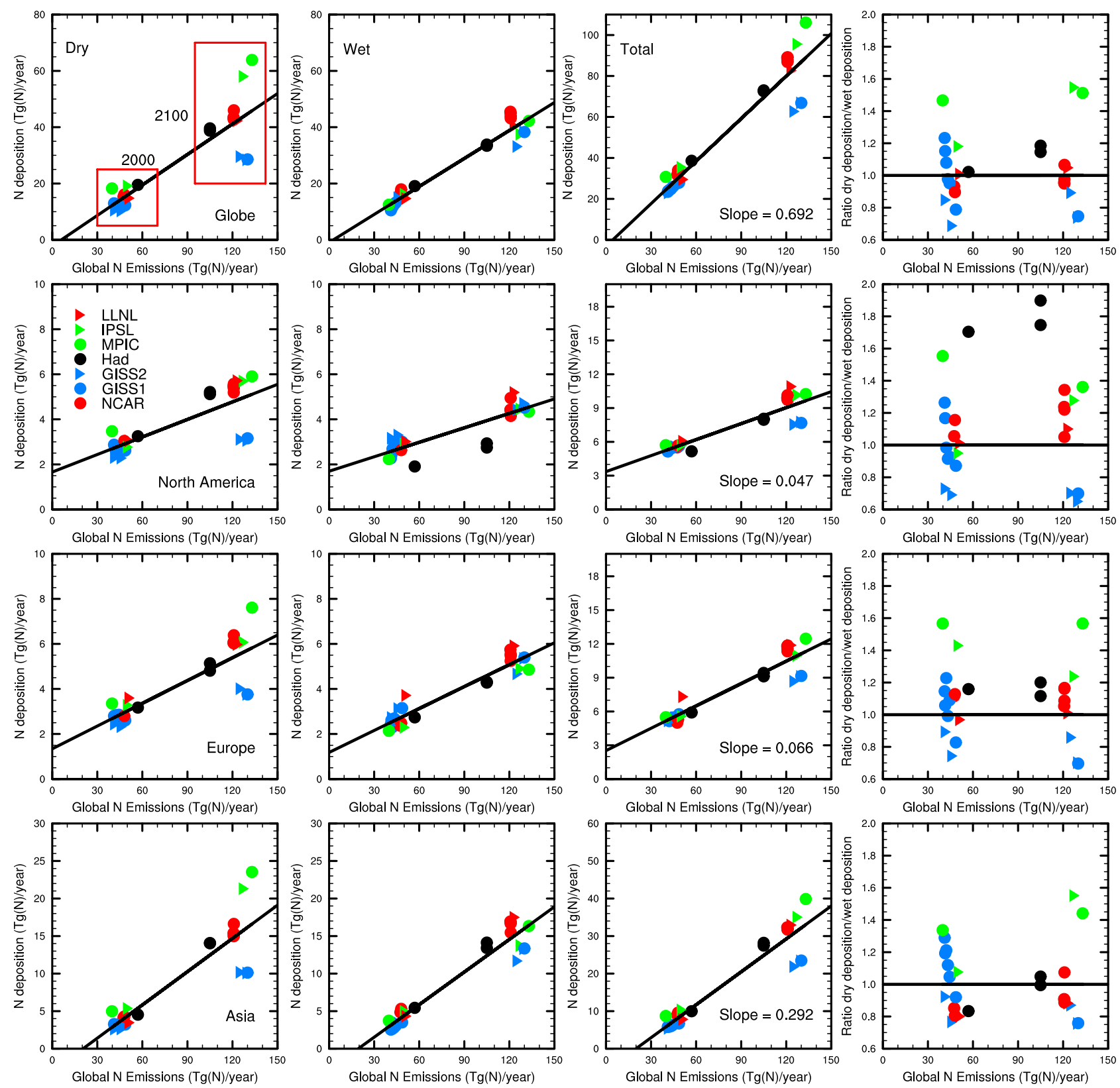

Figure 5. Scatterplot of the integrated nitrogen deposition (in $\operatorname{Tg}(\mathrm{N}) /$ year) over all land areas (first row), Asia (second row), North America (third row) and Europe (fourth row). The first column shows the results for dry deposition, the second column shows the results for wet deposition, the third column shows the results for the total, and the fourth column shows the results for the ratio of dry deposition over wet deposition. In all plots, the horizontal axis is the global emissions (including lightning) for each model. A least squares linear fit is performed independently for each plot in the first three columns; the slope is shown for the total deposition only.

tematic misrepresentation of precipitation in the models over Europe; however we cannot test this hypothesis because such fields were not saved at the time of the simulations.

[46] Over Asia, there is no nitrogen deposition climatology available yet. There is, however, an East Asia acid deposition network (EANET, see www.adorc.gr.jp/ eanet.html) that provides observations, albeit for 2001 only. To compare with our model results, we have used only the rural and remote stations, for a total of 25 stations covering eastern Asia (namely China, Japan, Mongolia, Republic of Korea and the Asian portion of the Russian Federation for the northeast sector and Indonesia, Malaysia, Philippines, Thailand, and Vietnam for the southeast sector). Results are displayed in Figure 3c and summarized in Table 3. All models tend to provide a reasonable description of the low deposition rates but underestimate the higher ones. Indeed, the models seem to only produce deposition rates smaller than $0.4 \mathrm{gN} / \mathrm{m}^{2} /$ year while observed values go up to $0.8 \mathrm{gN} / \mathrm{m}^{2} /$ year. It must, how- 

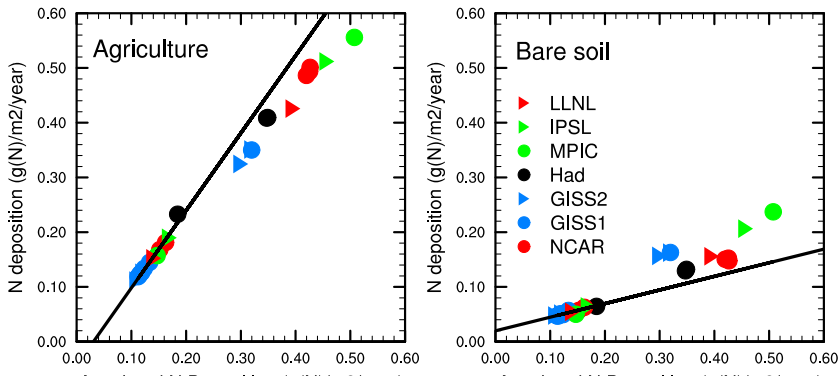

Avg. Land N Deposition ( $\mathrm{g}(\mathrm{N}) / \mathrm{m} 2 / \mathrm{year})$
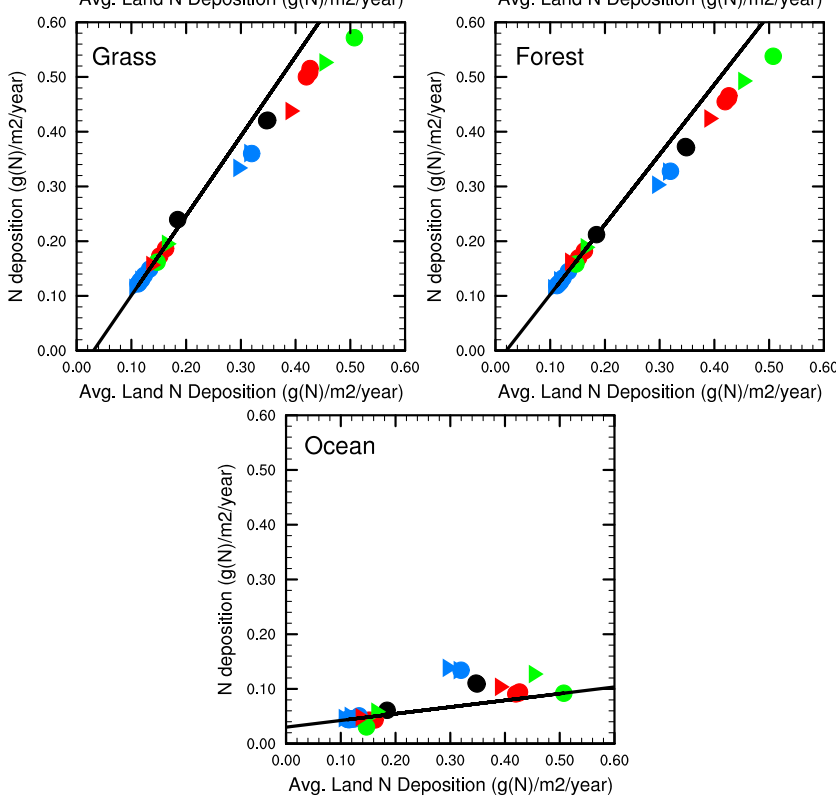

Figure 6. Scatterplot of the nitrogen deposition rate (in $\mathrm{gN} / \mathrm{m}^{2} /$ year) over a variety of ecosystems. A least squares linear fit is performed using the results for the 2000 emissions only.

ever, be remembered that we are here comparing T31 aggregated model results with a limited number of point observations. On average, the correlation coefficient is close to 0.6 , but with a significant underestimate of the mean and median deposition rate.

\subsection{Global Distribution of Nitrogen Deposition in 2000 and 2100}

[47] In this section, we discuss the large-scale annual distribution of nitrogen (using all deposited species contained in $\mathrm{NO}_{\mathrm{y}}$ ) deposition over land areas for presentday and 2100 conditions. In order to focus our analysis on the land areas only (since we are targeting the impact on the land carbon cycle), we have explicitly set the deposition rates over the ocean to 0 in Figure 4.

[48] In the present-day simulations (Figure 4a) the maximum deposition rates over land are between 1.2 and $1.5 \mathrm{gN} / \mathrm{m}^{2} /$ year. Depending on the model, these values are found over western Europe and/or China. In all simulations, the eastern United States is characterized by deposition rates of approximately $1 \mathrm{gN} / \mathrm{m}^{2} /$ year; in addition, the nitrogen deposition over Europe (similar in amplitude to the eastern United States) extends from the source region in western Europe all the way to the Ural Mountains $\left(120^{\circ} \mathrm{W}\right)$. Because the GISS emissions for 2000 are considerably smaller than the other models (see Table 2), large deposition rates over Asia and India are not found in their simulations.

[49] To summarize the model-to-model variability, we define a relative standard deviation of nitrogen deposition as the standard deviation (among models) of the annual deposition rate over each grid point divided by the mean deposition rate. Over most of the industrialized regions, this standard deviation is less than $45 \%$ (as the average interannual variability is of the order of $10 \%$ at the most (not shown), many of these features are statistically significant); on the other hand, the rest of the world exhibits standard deviations as high as $90 \%$, even where significant deposition occurs. This seems to be mostly due to a large variability in the biomass burning emissions of nitrogen species (mostly NO), especially over South America. As a consequence, the normalized standard deviation among model results is largest over the tropical regions. The analysis of the GISS simulations shows only a slight dependence on the various SST fields; this can be expected, as the present-day SST fields from the various climate models are quite similar (not shown).

[50] In the case of the 2100 simulations (Figure 4b), the dominant feature is the large increase over Asia (from India to China), with more than a tripling of the presentday deposition rates, in agreement with the expected changes in $\mathrm{NO}_{\mathrm{x}}$ emissions (see section 4). Significant growth is also expected over the already heavily deposited regions of Europe and North America; in particular, model results (except for GISS) indicate a large increase of nitrogen deposition over western Russia. Also, two models (MPIC and IPSL) indicate a large increase over North Africa, including Saudi Arabia. There is also an indication that the rate of increase will be slightly larger over the eastern United States than over Europe. On the annual timescale, the standard deviation is in most places less than $60 \%$; interestingly, there seems to be less intermodel variability in 2100 than in 2000. This is probably due to the increase of the "well-defined" anthropogenic emissions compared to less constrained natural (soils and biomass burning) emissions.

\subsection{Regional and Global, Wet and Dry Deposition}

[51] In this section, we discuss the nitrogen deposition over land in terms of regional and global aggregates. Four regions are defined: Asia $\left(60^{\circ} \mathrm{E}\right.$ to $150^{\circ} \mathrm{E}, 0^{\circ} \mathrm{N}$ to $\left.75^{\circ} \mathrm{N}\right)$, Europe $\left(15^{\circ} \mathrm{W}\right.$ to $45^{\circ} \mathrm{E}, 35^{\circ} \mathrm{N}$ to $\left.75^{\circ} \mathrm{N}\right)$, North America $\left(135^{\circ} \mathrm{W}\right.$ to $45^{\circ} \mathrm{W}, 25^{\circ} \mathrm{N}$ to $\left.75^{\circ} \mathrm{N}\right)$, and the globe. For each region, the annual integrated amount of nitrogen deposition over land is calculated for both wet and dry processes. In addition, we separate the role of wet and dry deposition by displaying the ratio of these quantities. While the underlying land area does not respond differently to dry versus wet deposition of nitrogen, this information gives insight into which process is responsible for the spread in the model results and an indication of their sensitivity to climate change.

[52] At the global scale (Figure 5, first row), the nitrogen deposition over land increases from $30 \mathrm{Tg}(\mathrm{N}) /$ year to approximately $80 \mathrm{Tg}(\mathrm{N}) /$ year between 2000 and 2100 . As indicated by the linear relationship (fitted using a least squares analysis of all the model results), the total nitrogen deposition corre- 


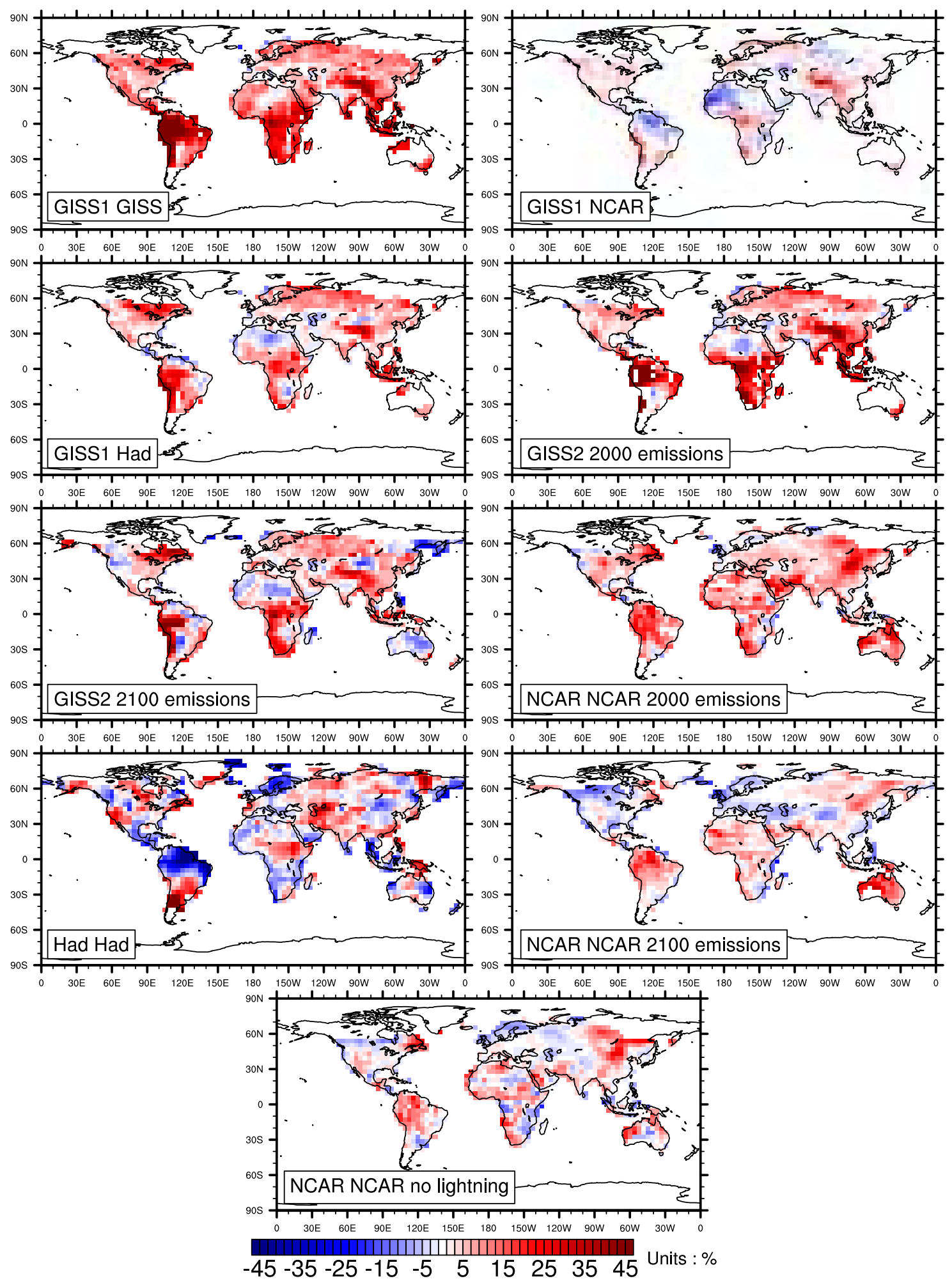

Figure 7a. Global distribution of the relative change (in \%) in the annual average nitrogen deposition rate (in $\mathrm{gN} / \mathrm{m}^{2} /$ year) over land areas from changes in climate as defined by equation (1). Each plot is referenced by the model used, followed by the SST field used and specifics about the model simulation.

lates quite well with the total nitrogen emissions (including lightning, see Table 2). This linear fit implies that, overall, most models deposit the same proportion of nitrogen emissions. For present-day conditions, this proportion is $60-70 \%$, very similar to Galloway et al. [2004, see Table 7]; this imbalance is compensated by oceanic deposition as models are at steady state or close to it. It is however important to note that, in 2100 , there are significant deviations from this linear fit; indeed, while the total emissions are quite similar between the GISS and the MPIC 2100 simulations, there is approxi- 


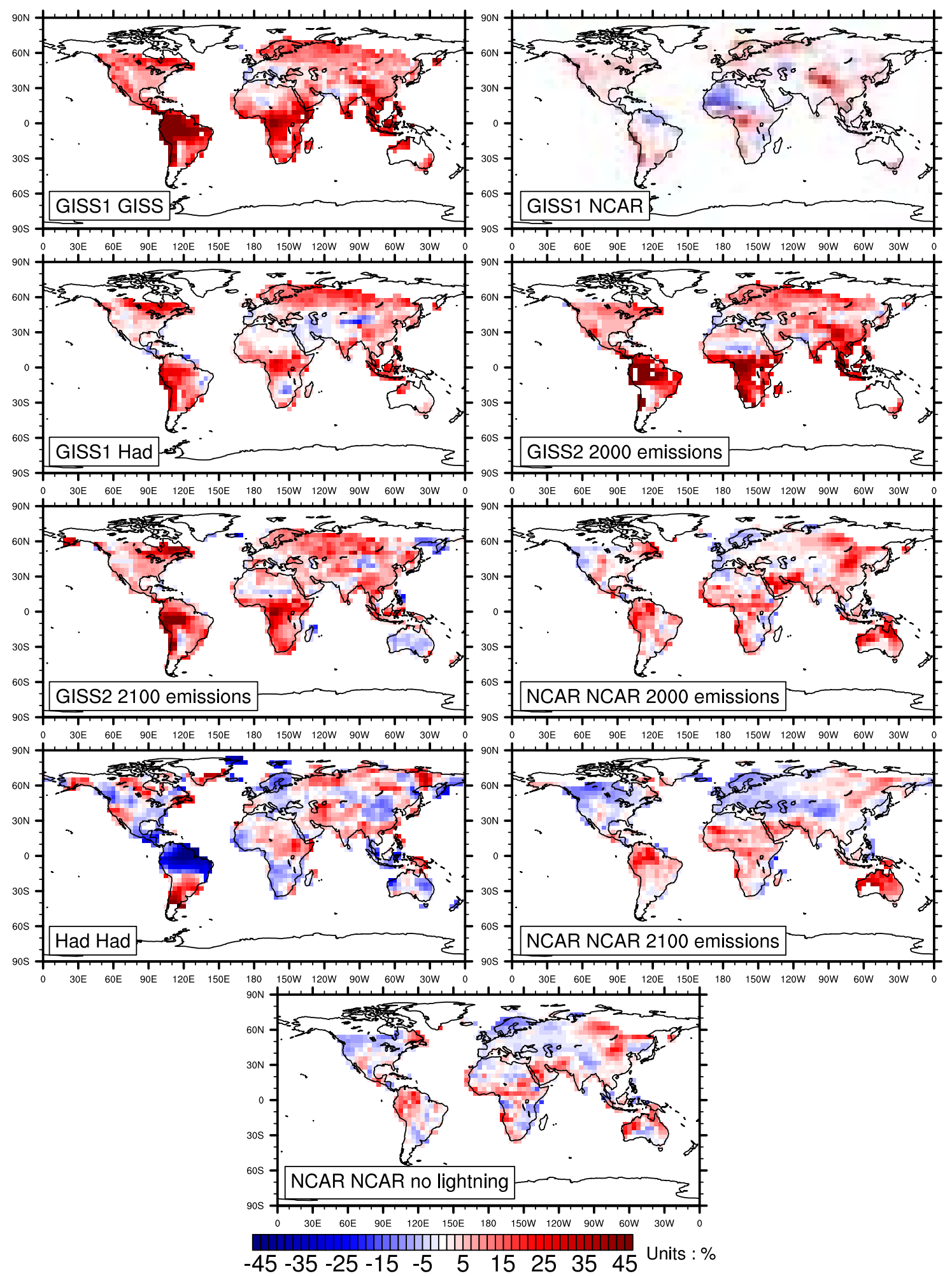

Figure 7b. Same as Figure 7a but for wet deposition (see equation (2)).

mately a $30 \%$ difference in the estimates of nitrogen deposition. In all regions, the emission-deposition correlation is much tighter for wet deposition than for dry deposition, which has significant outliers. In addition, there is indication that the ratio of dry deposition to wet deposition is likely to increase between 2000 and 2100, except for the GISS model; this relative increase in dry deposition implies that observational networks (in which the wet deposition is explicitly measured and the dry deposition inferred) will underestimate the increase in nitrogen deposition.

[53] Over North America, there is no consensus among models on which process will drive the near doubling of deposition rate; indeed this region has the largest spread for the ratio of dry versus wet deposition. Over this region the 


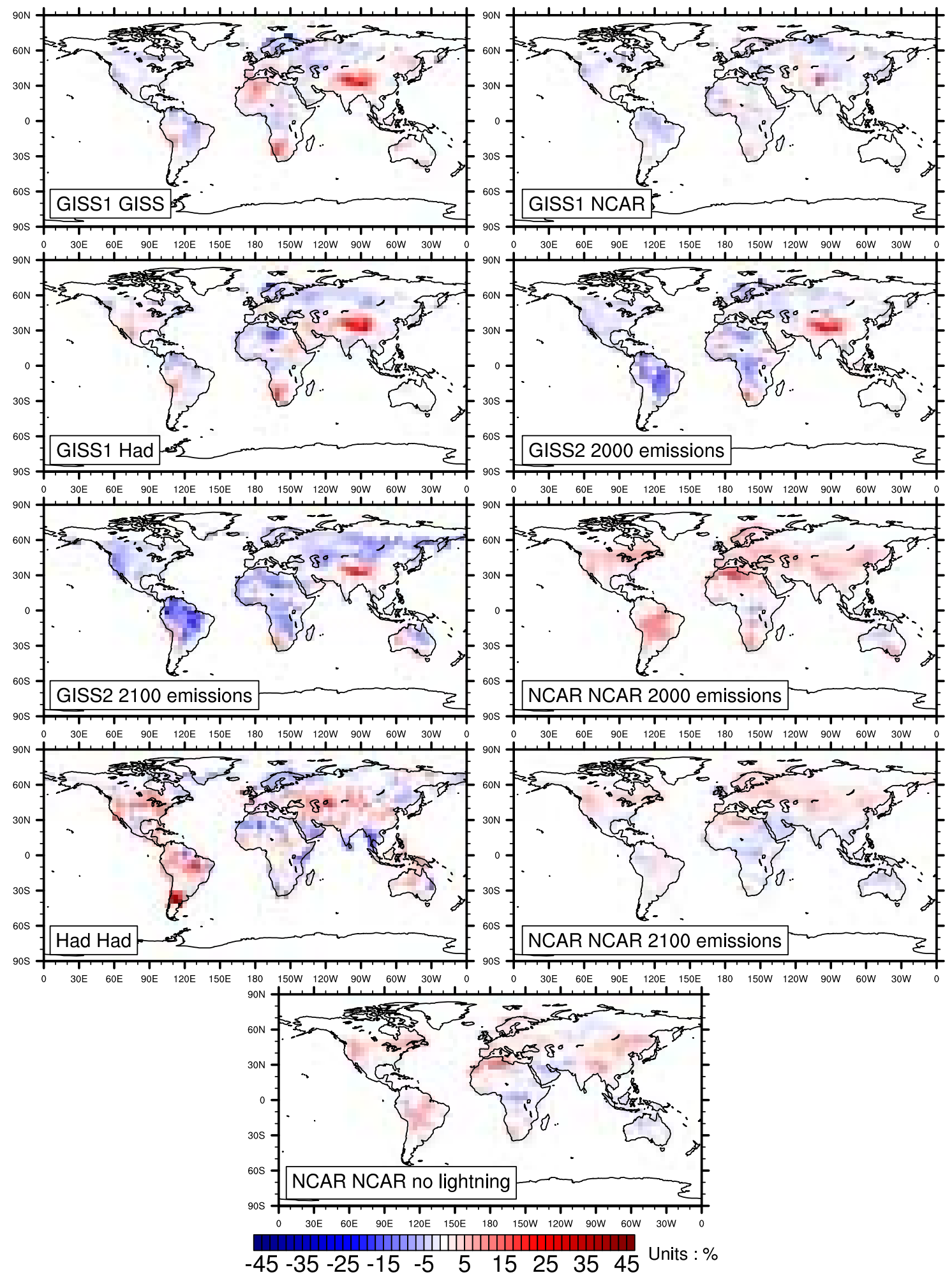

Figure 7c. Same as Figure 7a but for dry deposition (see equation (3)).

Had model exhibits a much lower wet deposition than any other model. This is true for both present-day and future conditions. This bias comes from a significantly lower deposition rate over the western United States, while the eastern portion is quite well simulated (see Figure $3 \mathrm{a}$ and Table 3). Over Europe, there is little modification to the dry/ wet deposition rates between present day and 2100. The relative increase in total deposition is very similar to the North American region, i.e., a near doubling. Finally, over Asia, by 2100, the amount of deposition corresponds to slightly less than half of the global nitrogen deposition over land, from approximately a third in 2000 , a consequence of 

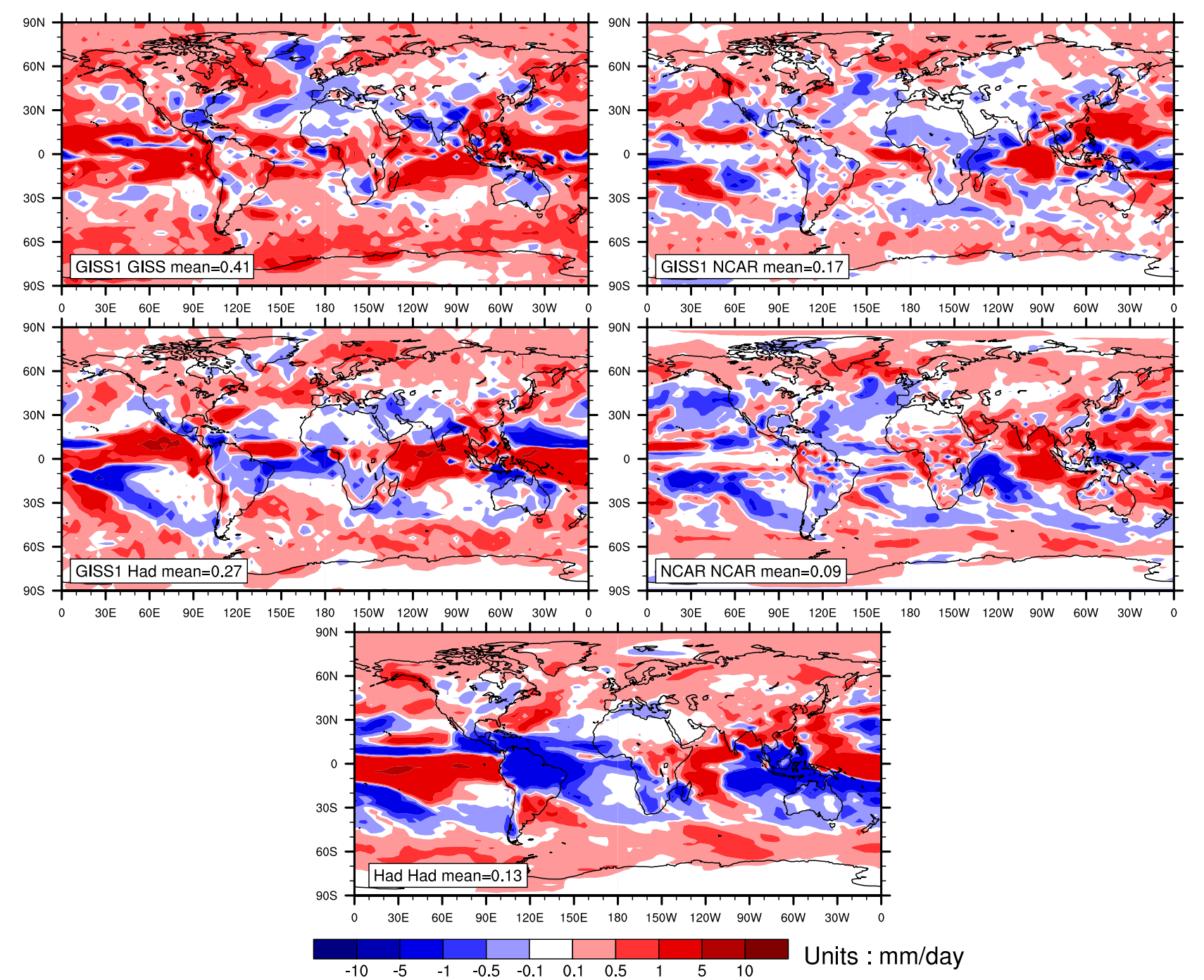

Figure 8. Change in annual precipitation (2100 minus 2000, in $\mathrm{mm} / \mathrm{day}$ ). Each plot is referenced by the model used, followed by the SST field used. In addition, the global average of this difference is indicated in each label.

the large $\mathrm{NO}_{\mathrm{x}}$ emission increase over Asia. The ratio of dry versus wet deposition is more compact than for the other regions, especially in 2000.

\subsection{Deposition on Separate Ecosystems}

[54] In this section, we document the deposition on a set of ecosystems, namely agriculture, bare soil, grass, forest and ocean. It must be noted that this analysis is only valid for the CLM land cover map and that no changes in land cover between 2000 and 2100 are considered here [Bonan et al., 2002].

[55] Because the impact of nitrogen deposition is very ecosystem-dependent [Townsend et al., 1996; Waldorp et al., 2004], this analysis identifies the amount of nitrogen deposition that each ecosystem receives (Figure 6). In Figure 6, we compare the average nitrogen deposition rate (in $\mathrm{gN} / \mathrm{m}^{2} /$ year) over a specific ecosystem (abscissa) to the average nitrogen deposition rate over all landmasses. In addition, a linear fit is calculated using the modeled nitrogen deposition rates for the present-day emissions. Deviation from this linear relationship for 2100 emissions indicates that agriculture, grass and forest land areas are expected to receive proportionally a smaller fraction of the 2100 nitrogen emissions than under present-day conditions. In contrast, the rate for bare soils and ocean is going to increase proportionally faster than the total land deposition. This effect seems to be slightly reinforced when climate change is considered (not shown). The increased contribution over the oceans is partly due to the increased fraction of emissions concentrated in the coastal regions, especially in Africa and Asia (see Figure 2).

[56] In terms of nitrogen-carbon coupling, it is mostly the forested areas that can contribute significantly to a long-term potential carbon sink as it is characterized by a high C:N ratio and a slow turnover time [Townsend et al., 1996]. In this analysis, we found that, over the forested areas, the average nitrogen deposition rate is expected to increase from a global average of $0.15(0.12-0.22) \mathrm{gN} / \mathrm{m}^{2} /$ year to $0.42 \mathrm{gN} / \mathrm{m}^{2} /$ year $(0.3-0.54)$. In terms of integrated amounts, the mean values translate to $10 \mathrm{TgN} / y e a r$ and $28 \mathrm{TgN} /$ year, respectively. If no saturation takes place, this implies that approximately 3 times 
as much carbon can be taken up by the forested areas in 2100 compared to present-day conditions.

\subsection{Impact of Climate Change Only}

[57] As shown in previous sections, large changes in nitrogen deposition are expected to occur by 2100 as a result of changes from emissions and from climate (precipitation, temperature, water vapor, and transport). In this section, we try to identify the fraction due to climate change only. For this purpose, a set of simulations with 2100 climate and 2000 emissions (and vice versa) were performed (see Table 1). The sensitivity is calculated as the relative difference (expressed in \%)

$$
\frac{\operatorname{Ndep}(2100)-\operatorname{Ndep}(2000)}{\operatorname{Ndep}(2000)}
$$

where Ndep is the total wet and dry nitrogen deposition over land, annual average for the considered climate states (2100 and 2000). This ratio was calculated from simulations using either 2000 or 2100 emissions.

[58] From the available model simulations (Figure 7a, see Table 1) the relative nitrogen deposition change due to climate change alone ranges from a positive increase only (GISS model with the GISS SSTs) to a very mixed signal as in the Had model. Except for the decrease over Central Africa, there seems to be very little consensus between models on what is the sensitivity of nitrogen deposition to climate. This is true even when the same SST perturbations are used to drive the climate of different models. As the average interannual variability is of the order of $10 \%$ at the most (not shown), many of the features due to climate change alone are statistically significant. The wide range of sensitivities is an indication that changes in precipitation between 2000 and 2100 are highly variable between models (Figure 8).

[59] From the analysis of the nitrogen deposition in the GISS2 and NCAR simulations, there is not much difference in the sensitivity to climate whether 2000 or 2100 emissions are used. From these simulations, only small regional changes are found while the large-scale patterns are almost identical.

[60] In addition, since the NO lightning source is climatedependent, the NCAR model performed complementary simulations in which this source was removed. In this case, the removal of the lightning source does very little to the overall results. This is, however, not surprising since the lightning source in the NCAR model indicates a small absolute sensitivity (from $2 \mathrm{Tg} / \mathrm{yr}$ to $2.8 \mathrm{Tg} / \mathrm{yr}$ ) from climate changes. To the contrary, a large fraction of the increase in the GISS model over the tropics is due to increased lightning activity. Similarly, the large decrease over South America in the Had model is associated with an anomalous drying (see Figure 8); this has the consequence of reducing wet removal and decreasing the lightning source.

[61] To differentiate the role of wet and dry processes, we display (Figures $7 \mathrm{~b}$ and $7 \mathrm{c}$, respectively) the following diagnostics

$$
\frac{\text { Ndepwet(2100) - Ndepwet(2000) }}{\operatorname{Ndep}(2000)}
$$

and

$$
\frac{\operatorname{Ndepdry}(2100)-\operatorname{Ndepdry}(2000)}{\operatorname{Ndep}(2000)}
$$

[62] The sum of equations (2) and (3) is equivalent to the results display in Figure 7a for equation (1). The analysis of these figures indicates that wet deposition is indeed the largest contributor to the changes in nitrogen deposition from climate change. However, changes in dry deposition are nontrivial. For example, the GISS2 simulations indicate a very large decrease from 2000 to 2100 over South America; this actually opposite to the (larger) impact on wet deposition. Over the same region, both Had and NCAR indicate an increase in nitrogen deposition.

[63] Overall, this analysis indicates that wet deposition is the main deposition process affected by climate change. Consequently, models which have a propensity to simulate the nitrogen deposition through dry processes are likely to display a lower sensitivity to climate change.

\section{Discussion and Conclusions}

[64] We have used a multimodel approach to analyze the distribution and amplitude of nitrogen deposition over land under present-day and 2100 conditions. In addition to a variety of models, various sets of emissions and climate conditions were used to span a wider range of possible states. The purpose of creating such a large ensemble is that the simulated range of results provides a lower bound for the overall uncertainty in the nitrogen deposition rates.

[65] Under present-day conditions, the results form this study show that the integrated deposition over land ranges between 25 and $40 \mathrm{Tg}(\mathrm{N}) /$ year. By 2100, under the A2 scenario, the deposition over land is expected to range between 60 and $80 \mathrm{Tg}(\mathrm{N}) /$ year. For most models, the deposition over land amounts to approximately $70 \%$ of the total nitrogen emitted (from surface sources and lightning) regardless of the climate state or the amount of nitrogen emissions. The remainder is deposited over the oceans.

[66] While models tend to produce similar deposition amounts over land for a given set of emissions, the split between dry and wet deposition rates is very modeldependent. In addition, there is indication that dry deposition over land will increase slightly faster than wet deposition between 2000 and 2100, most likely from increased rapid deposition in the vicinity of the large source areas.

[67] Using the nitrogen emissions from the A2 scenario (usually considered the worst-case scenario), we have found that climate change only plays a minor role (a maximum of $50 \%$ from climate change versus a $2-3$ fold increase from emissions) in the modeled nitrogen distribution in 2100. However, the role of climate change could become more prominent under less drastic nitrogen emissions. In all cases, the nitrogen deposition by precipitation is the most affected by climate change; because no consideration of ammonium nitrate was given, this conclusion might be slightly overestimated owing to the slower wet removal of ammonium nitrate compared to nitric acid. 
[68] It was also shown that, using the CLM land cover map and without consideration of land use changes, agricultural, grassy, and forest areas are expected to receive a similar increase in their deposition rate; this increase is however slower than the increase of the average nitrogen deposition over land. On the other hand, bare soils and ocean will receive proportionally more in 2100 than in 2000. Over the forested areas, the average nitrogen deposition rate is expected to increase from $0.15(0.12-$ $0.22) \mathrm{gN} / \mathrm{m}^{2} /$ year to $0.42 \mathrm{gN} / \mathrm{m}^{2} /$ year $(0.3-0.54)$. In terms of integrated amounts, this translates to $10 \mathrm{TgN} /$ year and $28 \mathrm{TgN} /$ year, respectively.

[69] It is clear that the analysis presented in this paper only pertains to the nitrogen emitted as $\mathrm{NO}$ or $\mathrm{NO}_{2}$. Analysis from two models in which ammonia emissions and chemistry were considered indicates a similar response of ammonia and ammonium nitrate deposition to changes in emissions. Therefore the lack of ammonia emissions in this study implies that the deposition rates can only be larger than documented here, possibly by a factor of 2 [Holland et al., 1997; Galloway et al., 2004].

[70] This analysis of a possibly important chemistryclimate interaction can be seen as the first step toward a comprehensive Earth system modeling approach to climate change. We will discuss the implications on the carbon cycle in a follow-up paper.

[71] Acknowledgments. We would like to thank T. Holloway for bringing to our attention the EANET deposition data. F. Dentener, L. Emmons, and C. Nevison provided constructive comments on an earlier version of this manuscript. Three anonymous reviewers have provided very valuable input to improve this document. Funding for the 2003 and 2004 SANTA FE workshops was provided by CCSM and the NCAR Atmospheric Chemistry Division. Participants to those workshops but who did not directly contribute to this paper are also thanked for the valuable participation in the discussions. J.F.L. was supported by the SciDAC project from the Department of Energy. The National Center for Atmospheric Research is operated by the University Corporation for Atmospheric Research under sponsorship of the National Science Foundation. This paper is dedicated to the memory of my father.

\section{References}

Balkanski, Y. J., D. J. Jacob, G. M. Gardner, W. C. Graustein, and K. K. Turekian (1993), Transport and residence times of tropospheric aerosols inferred from a global three-dimensional simulation of $210 \mathrm{~Pb}, J$. Geophys. Res., 98, 20,573-20,586.

Bonan, G. B., et al. (2002), The land surface climatology of the Community Land Model coupled to the NCAR Community Climate Model, J. Clim., $15,3123-3149$.

Brasseur, G. P., et al. (1998), MOZART: A global chemical transport model for ozone and related chemical tracers: 1. Model description, J. Geophys. Res., 103, 28,265-28,290.

Collins, W. D., et al. (2005), The Community Climate System Model, version 3, J. Clim., in press.

Cubasch, U., et al. (2001), Projections of future climate change, in Climate Change 2001, pp. 525-582, Cambridge Univ. Press, New York.

DeMore, W. B., S. P. Sander, D. M. Golden, R. F. Hampson, M. J. Kurylo, C. J. Howard, A. R. Ravishankara, C. E. Kolb, and M. J. Molina (1997), Chemical kinetics and photochemical data for use in stratospheric modeling, JPL Publ., 97-4, Jet Propul. Lab., Pasadena, Calif.

Douglass, A., R. B. Rood, S. R. Kawa, and D. J. Allen (1997), A three dimensional simulation of the evolution of the middle latitude winter ozone in the middle stratosphere, J. Geophys. Res., 102, 19,217-19,232.

Galloway, J. N., et al. (2004), Nitrogen cycles: Past, present, and future, Biogeochemistry, 70, 153-226.

Gauss, M., et al. (2003), Radiative forcing in the 21 st century due to ozone changes in the troposphere and the lower stratosphere, J. Geophys. Res., 108(D9), 4292, doi:10.1029/2002JD002624.

Gedney, N., P. M. Cox, and C. Huntingford (2004), Climate feedback from wetland methane emissions, Geophys. Res. Lett., 31, L20503, doi:10.1029/2004GL020919.
Giorgi, F., and W. L. Chameides (1986), Rainout lifetimes of highly soluble aerosols and gases as inferred from simulations with a general circulation model, J. Geophys. Res., 91, 14,367-14,376.

Granier, C., et al. (2004), Present and future surface emissions of atmospheric compounds, Eur. Comm. Rep. EVK 2199900011, Eur. Comm., Brussels.

Guenther, A., et al. (1995), A global model of natural volatile organic compound emissions, J. Geophys. Res., 100, 8873-8892.

Hack, J. J. (1994), Parameterization of moist convection in the National Center for Atmospheric Research community climate model (CCM2), J. Geophys. Res., 99, 5551-5568.

Hauglustaine, D. H., et al. (2004), Interactive chemistry in the Laboratoire de Météorologie Dynamique general circulation model: Description and background tropospheric chemistry evaluation, J. Geophys. Res., 109, D04314, doi:10.1029/2003JD003957.

Holland, E. A., et al. (1997), Variations in the predicted spatial distribution of atmospheric nitrogen deposition and their impact on carbon uptake by terrestrial ecosystems, J. Geophys. Res., 102, 15,849-15,866.

Holland, E. A., B. H. Braswell, J. Sulzman, and J.-F. Lamarque (2005), Nitrogen deposition onto the United States and Western Europe: Synthesis of observations and models, Ecol. Appl., 15(1), 38-57.

Holtslag, A. A. M., and B. A. Boville (1993), Local versus nonlocal boundary layer diffusion in a global climate model, J. Clim., 6, 1825-1841.

Horowitz, L. W., et al. (2003), A global simulation of tropospheric ozone and related tracers: Description and evaluation of MOZART, version 2, J. Geophys. Res., 108(D24), 4784, doi:10.1029/2002JD002853.

Jacobson, M. A. (1995), Computation of global photochemistry with SMVGEAR II, Atmos. Environ., Part A, 29, 2541-2546.

Jenkinson, D. S., K. Goulding, and D. S. Powlson (1999), Nitrogen deposition and sequestration, Nature, 400, 629.

Johns, T. C. (2003), Anthropogenic climate change for 1860 to 2100 simulated with the HadCM3 model under updated emissions scenarios, Clim. Dyn., 20, 583-612, doi:10.1007/s00382-002-0296-y.

Krinner, G., et al. (2005), A dynamical global vegetation model for studies of the coupled atmosphere-biosphere system, Global Biogeochem. Cycles, 19, GB1015, doi:10.1029/2003GB002199.

Lawrence, M. G., P. J. Crutzen, P. J. Rasch, B. E. Eaton, and N. M. Mahowald (1999), A model for studies of tropospheric photochemistry: Description, global distributions, and evaluation, J. Geophys. Res., 104, 26,245-26,277.

Lawrence, M. G., et al. (2003), Global chemical weather forecasts for field campaign planning: predictions and observations of large-scale features during MINOS, CONTRACE, and INDOEX, Atmos. Chem. Phys., 3, $267-289$.

Lin, S. J., and R. B. Rood (1996), A fast flux form semi-Lagrangian transport scheme on the sphere, Mon. Weather Rev., 124, 2046-2070.

Liu, H., D. J. Jacob, I. Bey, and R. M. Yantosca (2001), Constraints from $210 \mathrm{~Pb}$ and $7 \mathrm{Be}$ on wet deposition and transport in a global three-dimensional chemical tracer model driven by assimilated meteorological fields, J. Geophys. Res., 106, 12,109-12,128.

Lurmann, F. W., A. C. Lloyd, and R. Atkinson (1986), A chemical mechanism for use in long-range transport/acid deposition computer modeling, J. Geophys. Res., 91, 10,905-10,936.

Mahowald, N. M., R. G. Prinn, and P. J. Rasch (1997a), Deducing CCl3F emissions using an inverse method and chemical transport models with assimilated winds, J. Geophys. Res., 102, 28,153-28,168.

Mahowald, N. M., P. J. Rasch, B. E. Eaton, S. Whittlestone, and R. G. Prinn (1997b), Transport of 222radon to the remote troposphere using the model of atmospheric transport and chemistry and assimilated winds from ECMWF and the National Center for Environmental Prediction/ NCAR, J. Geophys. Res., 102, 28,139-28,152.

Mari, C., D. J. Jacob, and P. Bechtold (2000), Transport and scavenging of soluble gases in a deep convective cloud, J. Geophys. Res., 105, 22,25522,267.

Matthews, E. (1983), Global vegetation and land use: New high-resolution data bases for climate studies, J. Clim. Appl. Meteorol., 22, 474-487.

Nadelhoffer, K. J., B. A. Emmett, and P. Gunderson (1999), Nitrogen deposition makes a minor contribution to carbon sequestration in temperate forests, Nature, 398, 145-148.

Nakicenovic, N., et al. (2000), IPCC Special Report on Emissions Scenarios, Cambridge Univ. Press, New York.

Oleson, K. W., et al. (2004), Technical description of the Community Land Model (CLM), Tech. Rep. NCAR/TN-461+STR, 174 pp., Natl. Cent. for Atmos. Res., Boulder, Colo.

Olivier, J. G. J., et al. (2001), Applications of EDGAR. Including a description of EDGAR 3.0: reference database with trend data for 1970-1995, RIVM Rep. 773301 001, Rijskinst. Voor Volksgezondh. en Milieu, Bilthoven, Netherlands.

Ollinger, S. V., J. D. Aber, P. B. Reich, and R. J. Freuder (2002), Interactive effects of nitrogen deposition, tropospheric ozone, elevated $\mathrm{CO} 2$ and land 
use history on the carbon dynamics of northern hardwood forests, Global Change Biol., 8, 545-562.

Penner, J. E., C. S. Atherton, and T. E. Graedel (1994), Global emissions and models of photochemically active compounds, in Global Atmospheric Biospheric Chemistry, edited by R. G. Prinn, pp. 223-247, Springer, New York.

Prather, M. J., et al. (2001), Atmospheric chemistry and greenhouse gases, in Climate Change 2001, pp. 239-287, Cambridge Univ. Press, New York.

Prentice, M. J., et al. (2001), The carbon cycle and atmospheric carbon dioxide, in Climate Change 2001, pp. 184-237, Cambridge Univ. Press, New York.

Price, C., and D. Rind (1994), Modeling global lightning distribution in a general circulation model, Mon. Weather Rev., 122, 1930-1939.

Price, C., J. Penner, and M. Prather (1997), NOx from lightning: 1. Global distribution based on lightning physics, J. Geophys. Res., 102, 59295941

Rasch, P. J., and J. E. Kristjansson (1998), A comparison of the CCM3 model climate using diagnosed and predicted condensate parameterizations, J. Clim., 11, 1587-1614

Rasch, P. J., and M. G. Lawrence (1998), Recent developments in transport methods at NCAR, Rep. 265, edited by B. Machenhauer, Max-PlanckInst., Hamburg, Germany.

Rasch, P. J., N. M. Mahowald, and B. E. Eaton (1997), Representations of transport, convection, and the hydrologic cycle in chemical transport models: Implications for the modeling of short-lived and soluble species, J. Geophys. Res., 102, 28,127-28,138.

Rotman, D. A., et al. (2004), IMPACT, the LLNL 3-D global atmospheric chemical transport model for the combined troposphere and stratosphere: Model description and analysis of ozone and other trace gases, J. Geophys. Res., 109, D04303, doi:10.1029/2002JD003155.

Sadourny, R., and K. Laval (1984), January and July performance of the LMD general circulation model, in New Perspectives in Climate Modeling, edited by A. Berger and C. Nicolis, pp. 173-197, Elsevier, New York.

Sander, S. P., et al. (2000), Chemical kinetics and photochemical data for use in stratospheric modeling: Supplement to evaluation 12-Update of key reactions, evaluation 13, JPL Publ. 00-003, Jet Propul. Labl., Pasadena, Calif.

Sanderson, M. G., W. J. Collins, R. G. Derwent, and C. E. Johnson (2003), Simulation of global hydrogen levels using a Lagrangian three-dimensional model, J. Atmos. Chem., 46, 15-28.

Schimel, D. S. (1995), Terrestrial ecosystems and the carbon cycle, Global Change Biol., 1, 77-91.

Schmidt, G. A., et al. (2005), Present day atmospheric simulations using GISS ModelE: Comparison to in-situ, satellite and reanalysis data, J. Clim., in press.

Schulze, E. D., W. Devries, and M. Hauhs (1989), Critical loads of nitrogen deposition on forest ecosystems, Water Air Soil Pollut., 48, 451-456.

Seinfeld, J. H., and S. N. Pandis (1998), Atmospheric Chemistry and Physics, John Wiley, Hoboken, N. J.

Shindell, D. T., G. Faluvegi, and N. Bell (2003), Preindustrial-to-presentday radiative forcing by tropospheric ozone from improved simulations with the GISS chemistry-climate GCM, Atmos. Chem. Phys., 3, 16751702.

Sievering, H. L. (1999), Nitrogen deposition and sequestration, Nature, 400, 630 .

Slingo, J. M. (1987), The development and verification of a cloud prediction scheme for the ECMWF model, Q. J. R. Meteorol. Soc., 113, 899927

Throop, H. L., E. A. Holland, W. J. Paron, D. S. Ojima, and C. A. Keough (2004), Effects of nitrogen deposition and insect herbivory on patterns of ecosystem-level carbon and nitrogen dynamics: results from the CENTURY model, Global Change Biol., 10, 1092-1105.

Tiedke, M. (1989), A comprehensive mass-flux scheme for cumulus parameterization in large scale models, Mon. Weather Rev., 117, 1779-1800.

Townsend, A. R., B. H. Braswell, E. A. Holland, and J. E. Penner (1996), Spatial and temporal patterns in terrestrial carbon storage due to the deposition of fossil-fuel nitrogen, Ecol. Appl., 6, 806-814.
Van der Werf, G. R., et al. (2003), Carbon emissions from fires in tropical and subtropical ecosystems, Global Change Biol., 9, 547-562.

Van Leer, B. (1977), Towards the ultimate conservative difference scheme. part IV: A new approach to numerical convection, J. Comput. Phys., 23, $276-299$

Vitousek, P. M., et al. (1997), Human alteration of the global nitrogen cycle: Sources and consequences, Ecol. Appl., 7, 737-750.

von Kuhlmann, R., M. G. Lawrence, P. J. Crutzen, and P. J. Rasch (2003a), A model for studies of tropospheric ozone and nonmethane hydrocarbons: Model description and ozone results, J. Geophys. Res., 108(D9), 4294, doi:10.1029/2002JD002893.

von Kuhlmann, R., M. G. Lawrence, P. J. Crutzen, and P. J. Rasch (2003b), A model for studies of tropospheric ozone and nonmethane hydrocarbons: Model evaluation of ozone-related species, J. Geophys. Res., 108(D23), 4729, doi:10.1029/2002JD003348.

Waldorp, M. P., D. R. Zak, R. L. Sinsabaugh, M. Gallo, and C. Lauber (2004), Nitrogen deposition modifies soil carbon storage through changes in microbial enzymatic activity, Ecol. Appl., 14, 1172-1177.

Walmsley, J. L., and M. L. Wesely (1996), Modification of coded parametrizations of surface resistances to gaseous dry deposition, Atmos. Environ., 30, $1181-1188$.

Walton, J. J., M. C. MacCracken, and S. J. Ghan (1998), A global-scale Lagrangian trace species model of transport, transformation, and removal processes, J. Geophys. Res., 93, 8339-8354.

Wang, Y., D. J. Jacob, and J. A. Logan (1998), Global simulation of tropospheric O3-NOx-hydrocarbon chemistry: 1. Model formulation, J. Geophys. Res., 103, 10,713-10,725.

Washington, W. M., et al. (2000), Parallel climate model (PCM) control and transient simulations, Clim. Dyn., 16, 755-774.

Wesely, M. L. (1989), Parameterizations for surface resistance to gaseous dry deposition in regional-scale numerical models, Atmos. Environ., 23, $1293-1304$

Wesely, M. L., and B. B. Hicks (2000), A review of the current status of knowledge on dry deposition, Atmos. Environ., 34, 2261-2282.

Wesely, M. L., D. R. Book, R. L. Hart, and R. E. Speer (1985), Measurements and parameterization of particulate sulfur dry deposition over grass, J. Geophys. Res., 90, 2131-2143.

Zhang, G. J., and N. A. McFarlane (1995), Sensitivity of climate simulations to the parameterization of cumulus convection in the Canadian Climate Centre general circulation model, Atmos. Ocean, 33, 407446

Zhang, M., W. Lin, C. B. Bretherton, J. J. Hack, and P. J. Rasch (2003), A modified formulation of fractional stratiform condensation rate in the NCAR Community Atmosphere Model (CAM2), J. Geophys. Res., 108(D1), 4035, doi:10.1029/2002JD002523.

G. P. Brasseur and C. Granier, Max-Planck Institute for Meteorology, D20146 Hamburg, Germany.

T. Butler and M. G. Lawrence, Max-Planck Institute for Chemistry, D55128 Mainz, Germany.

P. Cameron-Smith and D. Rotman, Lawrence Livermore National Laboratory, Livermore, CA 94550, USA.

W. D. Collins, P. G. Hess, E. A. Holland, J. T. Kiehl, J.-F. Lamarque, D. McKenna, P. Merilees, P. J. Rasch, and P. Thornton, National Center for Atmospheric Research, Boulder, CO 80305, USA. (lamar@ucar.edu) W. J. Collins, Hadley Centre, Met Office, Exeter, EX1 3PB, UK.

D. Hauglustaine, Laboratoire des Sciences du Climat et de l'Environnement/Institut Pierre-Simon Laplace, F-91191 Gif sur Yvette, France.

L. Horowitz, Geophysical Fluid Dynamics Laboratory/NOAA, Princeton, NJ 08542, USA.

M. J. Prather, Earth System Science, University of California, Irvine, CA 92697, USA.

D. Shindell, NASA Goddard Institute for Space Studies, New York, NY 10025, USA. 